\title{
State-of-the Art-Powerhouse, Dam Structure, and Turbine Operation and Vibrations
}

\author{
Zaher Mundher Yaseen ${ }^{1}{ }^{(1)}$, Ameen Mohammed Salih Ameen ${ }^{2}{ }^{(D)}$, \\ Mohammed Suleman Aldlemy ${ }^{3}$, Mumtaz Ali ${ }^{4}$, Haitham Abdulmohsin Afan ${ }^{5, *}$ (), Senlin Zhu ${ }^{6}$, \\ Ahmed Mohammed Sami Al-Janabi ${ }^{7}$, Nadhir Al-Ansari ${ }^{8, *(\mathbb{D})}$, Tiyasha Tiyasha ${ }^{9}$ \\ and Hai Tao ${ }^{10}$ \\ 1 Sustainable Developments in Civil Engineering Research Group, Faculty of Civil Engineering, Ton Duc \\ Thang University, Ho Chi Minh City, Vietnam; yaseen@tdtu.edu.vn \\ 2 Department of water resources engineering, Faculty of civil engineering, University of Baghdad, \\ Baghdad, Iraq; ameen.mohammed@coeng.uobaghdad.edu.iq \\ 3 Department of Mechanical Engineering, Collage of Mechanical Engineering Technology, Benghazi, Libya; \\ maldlemy@ceb.edu.ly \\ 4 Deakin-SWU Joint Research Centre on Big Data, School of Information Technology, Deakin University, \\ Victoria 3125, Australia; mumtaz.ali@deakin.edu.au \\ 5 Institute of Research and Development, Duy Tan University, Da Nang 550000, Vietnam \\ 6 State Key Laboratory of Hydrology-Water Resources and Hydraulic Engineering, Nanjing Hydraulic \\ Research Institute, Nanjing 210029, China; senlinzhu1989@gmail.com \\ 7 Department of Civil Engineering, Faculty of Engineering, University Putra Malaysia, Selangor 43400, Malaysia; \\ huffad@yahoo.com \\ 8 Civil, Environmental and Natural Resources Engineering, Lulea University of Technology, 97187 Lulea, Sweden \\ 9 Faculty of Civil Engineering, Ton Duc Thang University, Ho Chi Minh City, Vietnam; tiyadas51@gmail.com \\ 10 Department of Computer science, Baoji University of Arts and Sciences, Baoji, China; haitao@bjwlxy.edu.cn \\ * Correspondence: haithamabdulmohsinafan@duytan.edu.vn (H.A.A.); nadhir.alansari@ltu.se (N.A.-A.)
}

Received: 7 December 2019; Accepted: 17 February 2020; Published: 24 February 2020

check for updates

\begin{abstract}
Dam and powerhouse operation sustainability is a major concern from the hydraulic engineering perspective. Powerhouse operation is one of the main sources of vibrations in the dam structure and hydropower plant; thus, the evaluation of turbine performance at different water pressures is important for determining the sustainability of the dam body. Draft tube turbines run under high pressure and suffer from connection problems, such as vibrations and pressure fluctuation. Reducing the pressure fluctuation and minimizing the principal stress caused by undesired components of water in the draft tube turbine are ongoing problems that must be resolved. Here, we conducted a comprehensive review of studies performed on dams, powerhouses, and turbine vibration, focusing on the vibration of two turbine units: Kaplan and Francis turbine units. The survey covered several aspects of dam types (e.g., rock and concrete dams), powerhouse analysis, turbine vibrations, and the relationship between dam and hydropower plant sustainability and operation. The current review covers the related research on the fluid mechanism in turbine units of hydropower plants, providing a perspective on better control of vibrations. Thus, the risks and failures can be better managed and reduced, which in turn will reduce hydropower plant operation costs and simultaneously increase the economical sustainability. Several research gaps were found, and the literature was assessed to provide more insightful details on the studies surveyed. Numerous future research directions are recommended.
\end{abstract}

Keywords: dam sustainability; hydropower plant; Kaplan turbine; Francis turbine; kinetic energy; vibration effect 


\section{Introduction}

Dams are important hydraulic structures built across rivers to store excess water in their reservoirs for various purposes. Dams are classified based on different criteria, such as the materials used for its construction (e.g., embankment, masonry, or concrete dams); other forms of classification are based on the main structure of the dam and the appurtenances of the dam. This classification considers the importance of conduits, spillway, and the powerhouse of the dam. According to Zhang et al. [1], embankment dams account for about $72 \%$ of dams worldwide. Bosshard [2] indicated that more than $80 \%$ of the dams constructed in China and about $73 \%$ of dams constructed in Québec, Canada are embankment dams. Most of the previous dam incidents and failures were related to embankment dams, as many of the embankment dams are constructed using non-plastic or very low plasticity silt-sand-gravel, so they suffer from internal erosion, such as sinkholes, increased leakages, global backward erosion, suffusion, and internal instability [3]. Although internal erosion and piping due to seepage are the main causes of embankment dam failures, other reasons for embankment failures, such as overtopping due to extreme flood, shear slide, foundation issues, and seismic activity, should be considered [1].

In the late 19th-century, the hydro-turbine was introduced for producing electricity, which was constructed on Fox River in Appleton, Wisconsin, revolutionizing energy technology [4], marking the birth of hydropower technology. Exploiting hydropower has fewer environmental impacts than fossil-fuel-derived energy and simultaneously produces clean energy. However, studies have found that dam has led to the deterioration of water quality, soil erosion, spreading of snail-borne disease, endangering fish and animals, affecting agricultural land, landslides, uprooting millions of people, damaging infrastructure, sedimentation, and damaging the livelihood and environment [5-7]. According to Lejeune and Hui [8], 86.31\% of renewable worldwide-generated energy until 2008 (about 3247.3 TWH) was generated by hydropower. Despite being the largest contributor to clean energy, hydropower suffers from numerous constructional, operational, and maintenance issues, with the biggest issues being those related to turbines and their components. Hydro-turbines can be categorized into two types: reaction turbines (Francis and Kaplan types) and impulse turbines (Pelton type). The classification is important to identify the failures experienced by the type of turbine. The most common problems are cavitation, erosion, fatigue, and material-related faults [9]. However, reaction turbines mostly fail due to the cavitation problem, whereas impulse-type turbines are more likely to fail due to erosion $[10,11]$. The reaction-type turbines are the most commonly used turbines in the powerhouse as they operate with the submerges wheel and can be operated at a different head.

Hydroelectric power is a clean, renewable, and highly efficient source of electricity with enormous potential for improvement and expansion. The hydro-plant design is site-specific because the flow resources at any location are the main factors determining how much energy can be generated from the water. The two main flow resource parameters for a potential plant's energy-producing capacity are the river's hydrostatic head and its flow rate. The variability of sites has resulted in plants that generate less than $5 \mathrm{~kW}$ of power to the $22.5 \mathrm{GW}$ of the Three Gorges Dam in China [12]. This specificity provides a unique challenge for the engineers of each hydropower project.

Dams are mainly built to establish a head difference between the elevation of the water surface in the upper section of the dam (headrace) and the water surface downstream river of the dam (tailrace). The penstock, which is composed of tunnels or pipes, guides the water current to the turbine structure. The hydro-turbine is a machine-driven device that rotates due to the energy derived from the water flow. The mechanical energy of the water flow is transformed into electrical energy by an electric generator; the rotation of the electric generator is facilitated by a shaft that is connected to the gyrating turbine. As the water flow leaves the turbine, it is collected by the draft tube (a diffuser) and transferred downside of the river. Turbines are designed and selected according to the principle of energy transformation, available water head, specific speed of the turbine, and water quantity accessible for exploitation [13]. The stability of the dam and powerhouse is influenced by the vibration generated from the turbine operation. More detailed information about turbines are discussed later [13]. 
Several environmental factors such as earthquakes, which maintain dams in harmonic motion, add to the stress produced from dam powerhouse operational vibration. They also affect the stability of dams and often require a dynamic reaction to determine the acceleration, stresses, deformation due to seismic load [14]. Reducing such vibrational influence on dams is important to increase their stability. With the evolution of computer performance and development of programs that are specialized in modeling the influence of dynamic forces on structures, studies simulating the vibrational effects on dam bodies have increased the safety of these dams.

Civil engineers study the seismic effect on dam bodies to determine their dynamic behaviors. Two-dimensional (2D) numerical models that simulate the dynamic behavior of dam bodies were developed [15-17], followed by three-dimensional (3D) numerical models which certainly seem more applicable than 2D models as the structural behavior of dams is 3D in nature. In addition to that, dynamic acceleration is more sensitive to boundary conditions, thus difficult to be calculated accurately by the 2D model [14]. Similarly, other behaviors like embankment and stresses are more likely to be better analyzed by 3D models. Thus, it can be concluded that 3D models are more accurate than 2D models for the same purpose $[18,19]$. Mechanical engineers have examined the effect of vibration generated from the hydraulic turbines to determine their performance through the operational process and their hydraulic performance due to the operation of the powerhouse. Other studies [20-22] investigated and modeled the circulation of pressure in the turbine draft tube. A need remains to evaluate the influence of powerhouse-operation-related vibrational effects on the dam body; such studies must consider the dam, turbine, and powerhouse types. Modeling hydraulic performance and dynamic behaviors of embankment dams is important to improve dam safety during operation. However, this research area still lacks investigations on the effects of both seismic and vibration on the dam body due to powerhouse operation.

Vibration can cause problems in many mechanical and civil engineering projects; for example, wind load, earthquake, and water wave loading can cause vibration in many hydraulic structures such as bridges, gates of lock navigations, dams, and hydropower plants. The main objective of this study is to comprehensively review and assess the research conducted on powerhouse plants, turbines, and dam bodies from the standpoint of hydrostatic and fluid mechanic theories. This review provides insightful information on the improvement of dam safety and the protection of dams from the effects of both seismic and vibrational damage due to powerhouse operation.

\section{Dam Classification}

Dams have been classified into different types, but no clear and limited determinations and classifications exist that include several criteria based on their function, form, size, and selection of construction material. We discussed the vibrational effects on each type of dam, powerhouse component and facilities, and turbine.

The construction of dams requires consideration of several factors, as well as the participation of technical teams from various disciplines, such as structural, geotechnical, hydraulic and hydrological, and environmental engineering. During the construction of dams, the preliminary design must provide water storage and structural stability against overturning, sliding, and minimal seepage from the dams' foundation [23,24].

Dams play an enormous role in the development of societies. Dams are essential infrastructures contributing to prosperity and social development. Dams are built for several purposes: water supply, irrigation, flood control, hydropower, and recreation [25]. Dam failures are low-probability but high-loss events (financial loss and loss of life). Floods due to dam failures can be disastrous, threatening life and assets, especially when situated in urbanized areas. Hence, dam engineers have formulated with new methods of designing, constructing, and operating dams to ensure their safety [26]. The danger posed by most existing dams to downhill areas is still a serious concern, as many factors pose hazards, such as inadequate design, structural deterioration, poor operation, faulty construction, and poor maintenance [27]. 
Based on the structure and materials used in construction, dams can be categorized into several types, such as earth-fill, rock-fill, concrete, or masonry, which rely on gravity, arches, or buttress resistance [28]. Some dams are even constructed with a combination of different structures or materials. Earth-fill or rock-fill dams are called embankment dams. They can be constructed on several foundations, starting from weak deposits to strong rocks. The several components of a dam project include the structure for water retention (the dam), structure for water release (the spillway), structure for water conveyance (the conduit), and structure for the generation of hydropower generation (the power plants).

\subsection{Embankment Dams}

Embankment dams are constructed using excavated materials or materials sourced from another dam site [24]. These materials are arranged and compacted in layers without using any binding agent. The two main types of embankment dams normally built are earth-fill and rock-fill dams.

\subsubsection{Earth-Fill Dams}

This is the most economical type of dam where the locally available materials are used for the construction of the dam or if the underlying foundation is weak. These dams are mainly built from selected engineering soils that have been uniformly and intensively compacted within the thin layers and at a predetermined moisture content. Earth-filled dams efficiently resist forces exerted through main shear strength of soil [29]. Figure 1 depicts an example of an earth-fill embankment dam.

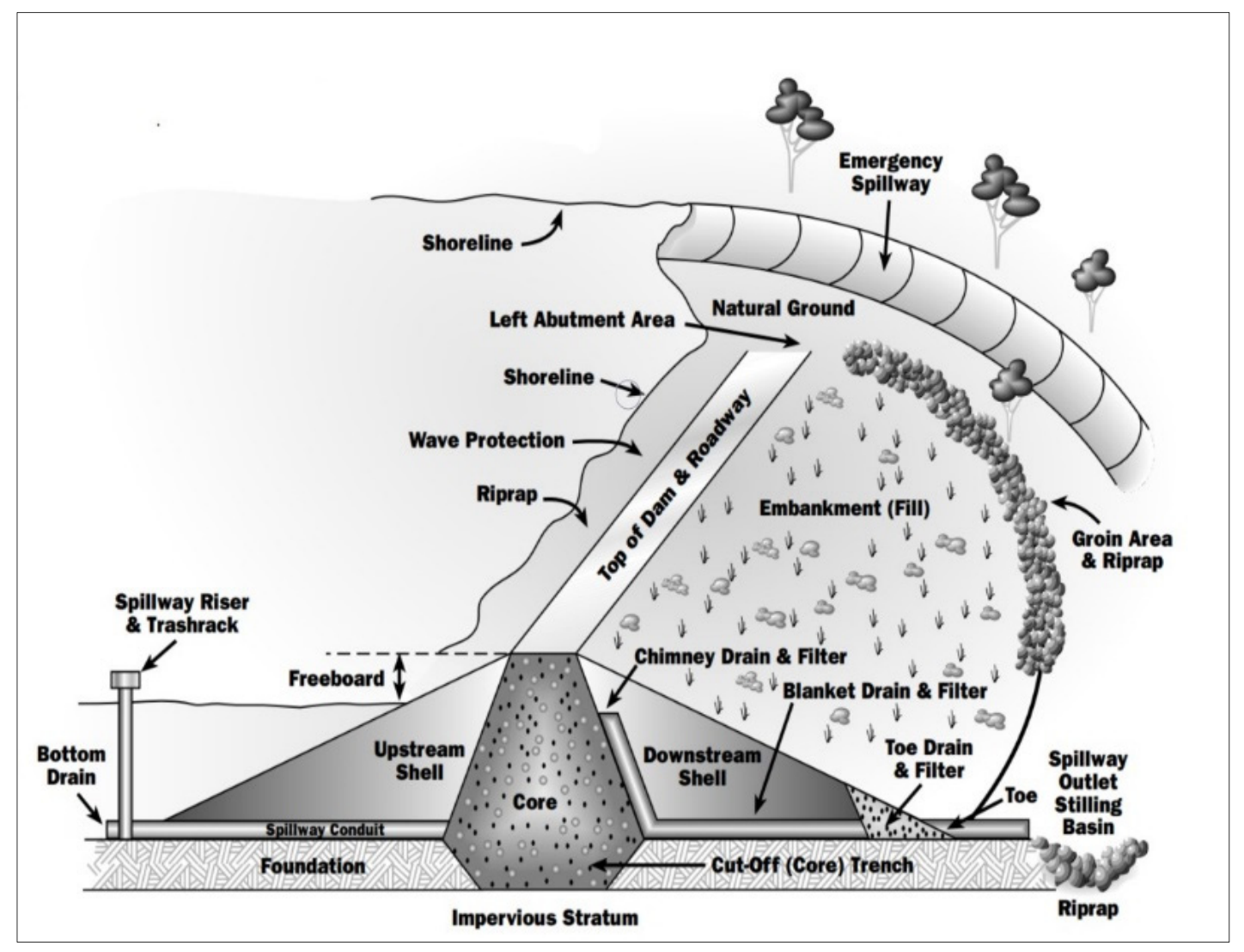

Figure 1. Cross-sectional view of earth-fill dam [30].

\subsubsection{Rock-Fill Dam}

Rock-fill dam design mainly includes crushed coarse-grained graves and an impervious layer of a slender concrete or compacted earth-fill. Figure 2 provides an example of a rock-fill dam with 
composition, rock foundation, and other basic components. The frictional forces between each piece of gravel confer stability to rock-fill dams, ensuring dam resistance to sliding failure during earthquakes.

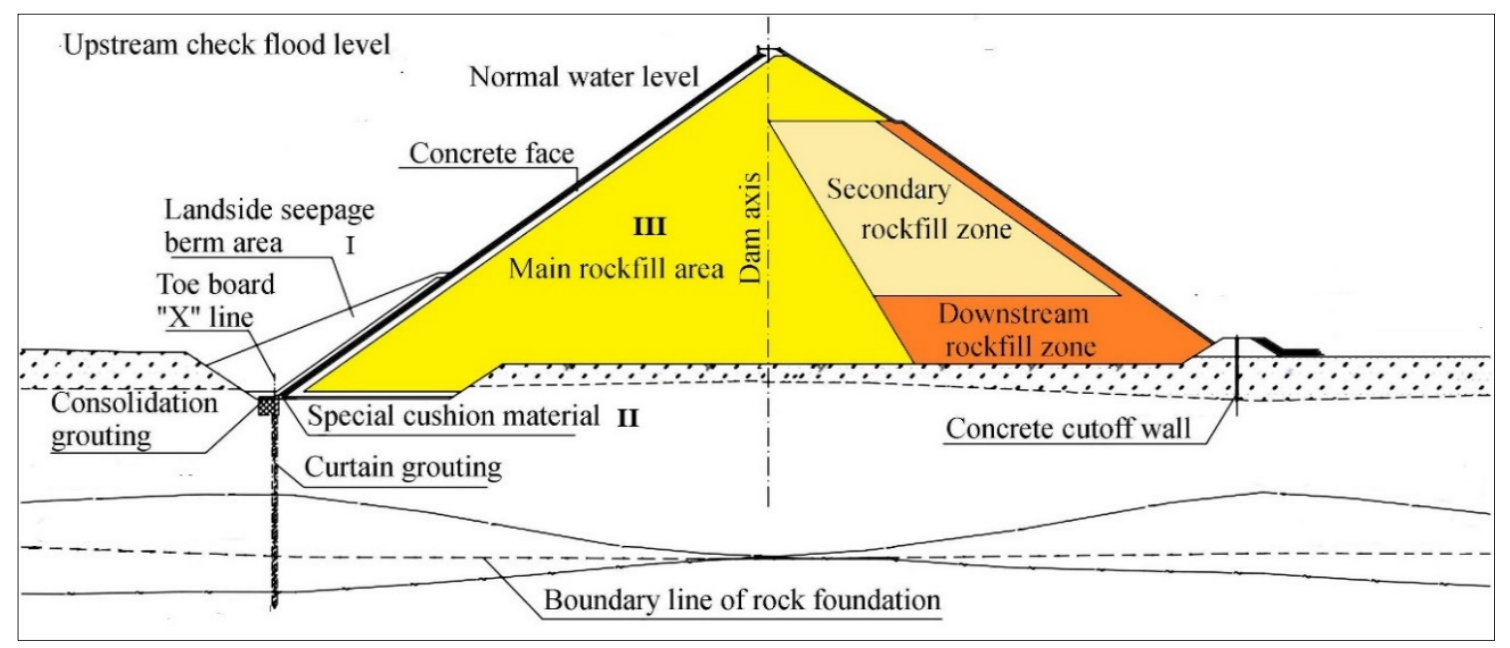

Figure 2. Diagram of concrete faced rock-fill dam [31]. The interior section can be divided into three zones: (1) Zone I, anti-seepage strengthening zone; (2) Zone II, cushion zone/second anti-seepage defense; and (3) Zone III, main embankment rock fill mass.

\subsection{Concrete Dams}

The mass construction of concrete dams began in about 1900 due to the ease of their construction and concrete's suitability for complex designs such as spillways or powerhouse inside the dam body [32]. From 1950 onward, mass concrete was strengthened with the aid of further substances like slag or pulverized gas ash to decrease temperature-induced problems or preclude cracking and decrease project costs. Many types of concrete dams are described and classified based on their shape as described below.

\subsubsection{Gravity Dams}

The stability of a gravity dam is a function of its mass. Although gravity dams are triangular, they are modified on the top for useful purposes and some are curved with the curvature facing upstream. These curves are mainly incorporated in the designs of these dams for both aesthetic and other reasons such as increased stability of the dam. A gravity dam can resist forces due to its own weight; the design ensures the stability and independence of each dam block [33]. Figure 3 presents the section and stability analysis during the uplift of the base due to flood or seepage when the upstream value becomes equivalent to the pressure exerted by the maximum water level. Uplift is the vertical force of water seeping below a dam. The pressure diagram becomes trapezoidal, as shown by the dotted line if no cut-off is provided in the base of the dam and at the downstream toe.

\subsubsection{Buttress Dams}

Buttress dams consist of a steady upward face supported at normal intervals using buttress partitions on the downstream part (Figure 4). These dams are lighter than the other dams; however, they are likely to produce larger stresses at the foundation [35]. The wall of the dam may be curved or flat and the hydrostatic pressure is transferred to the foundation via the slab. 


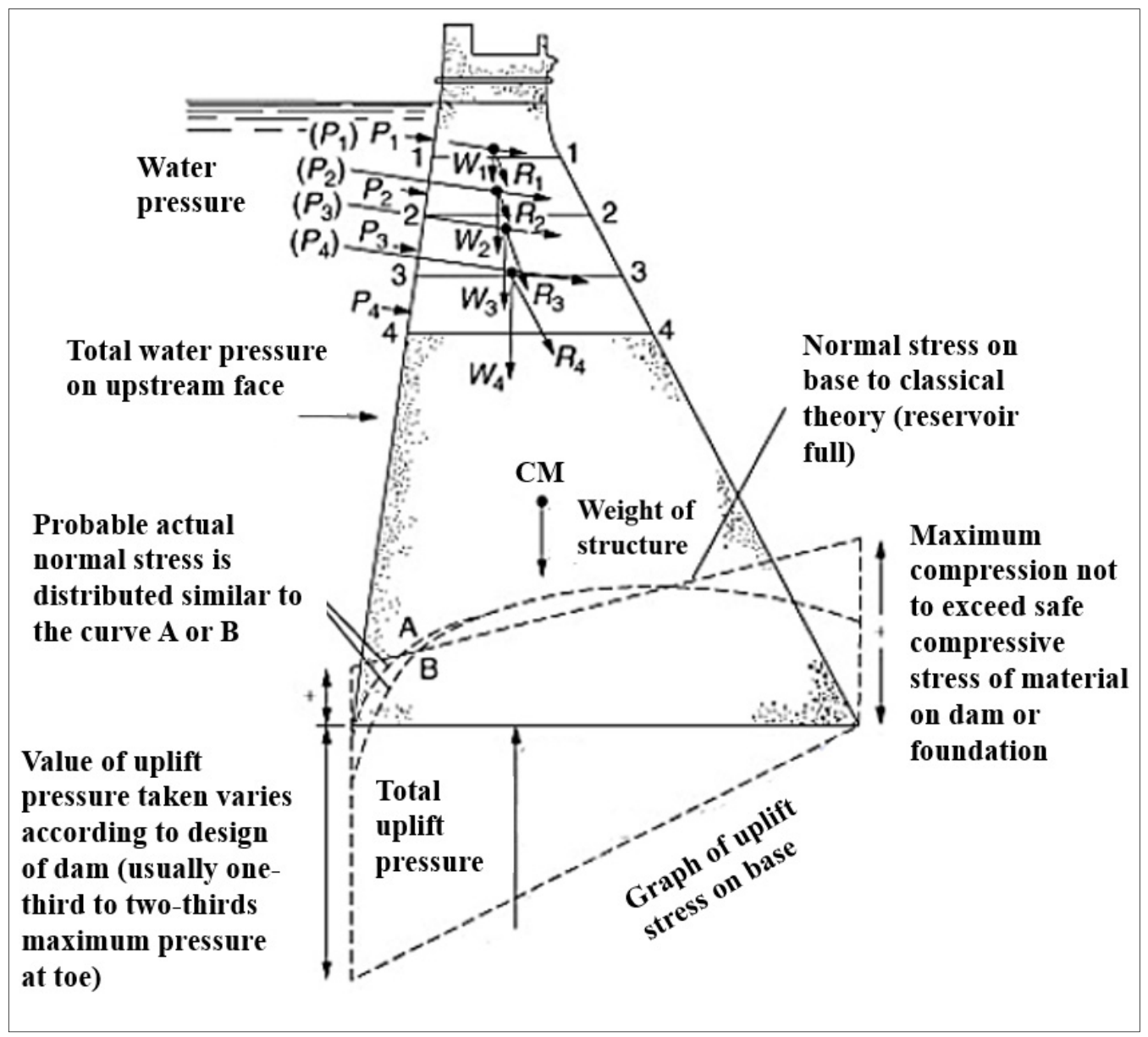

Figure 3. View of a gravity dam section and simple stability analysis during the uplift of the base [34].

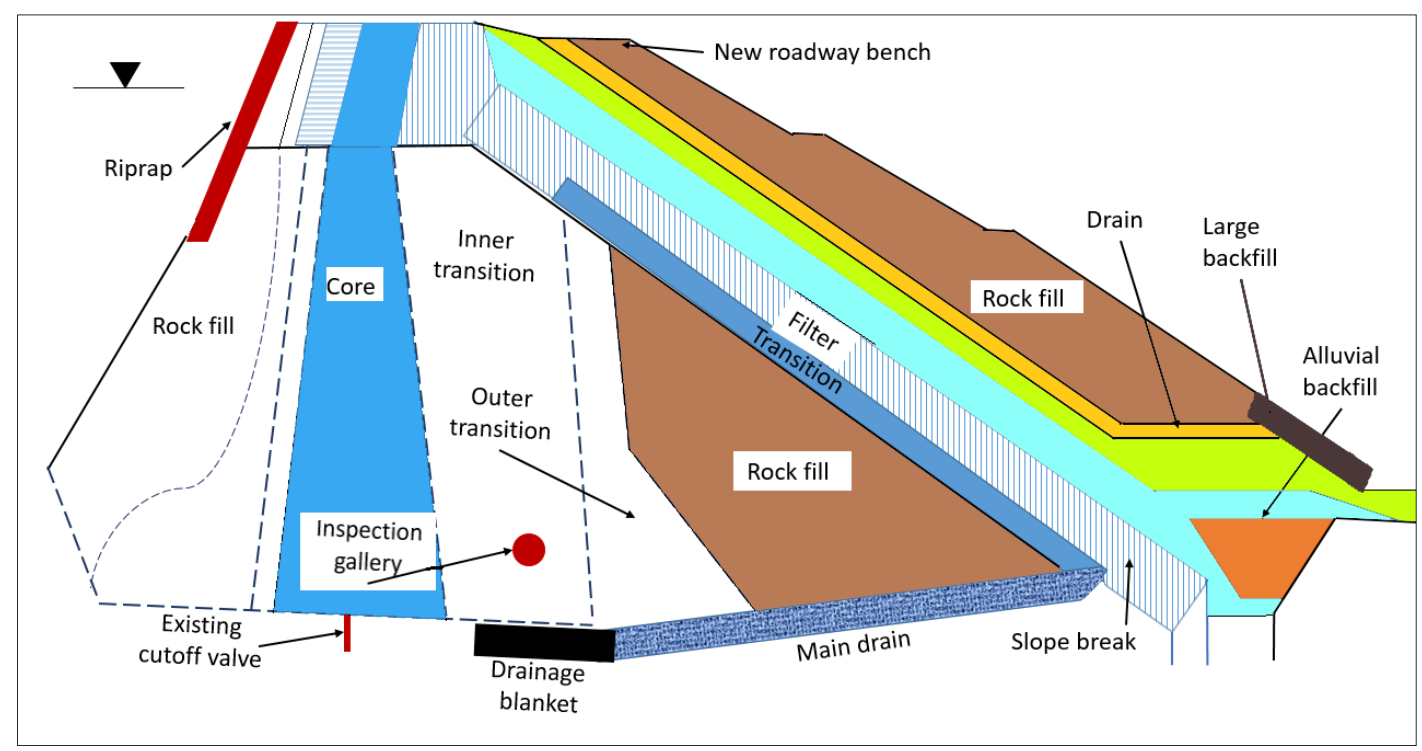

Figure 4. A cross-sectional view of the buttress dam, Iran [36].

\subsubsection{Arch Dams}

These dams, as shown in Figure 5, are built with large upstream curvatures; they rely on the arching action on the abutments and pass a significant portion of their water load to the river valley 
walls. They are structurally more efficient compared with gravity dams and commonly require less volume of concrete during construction. They resist the imposed forces by a combination of arch and cantilever actions [37].

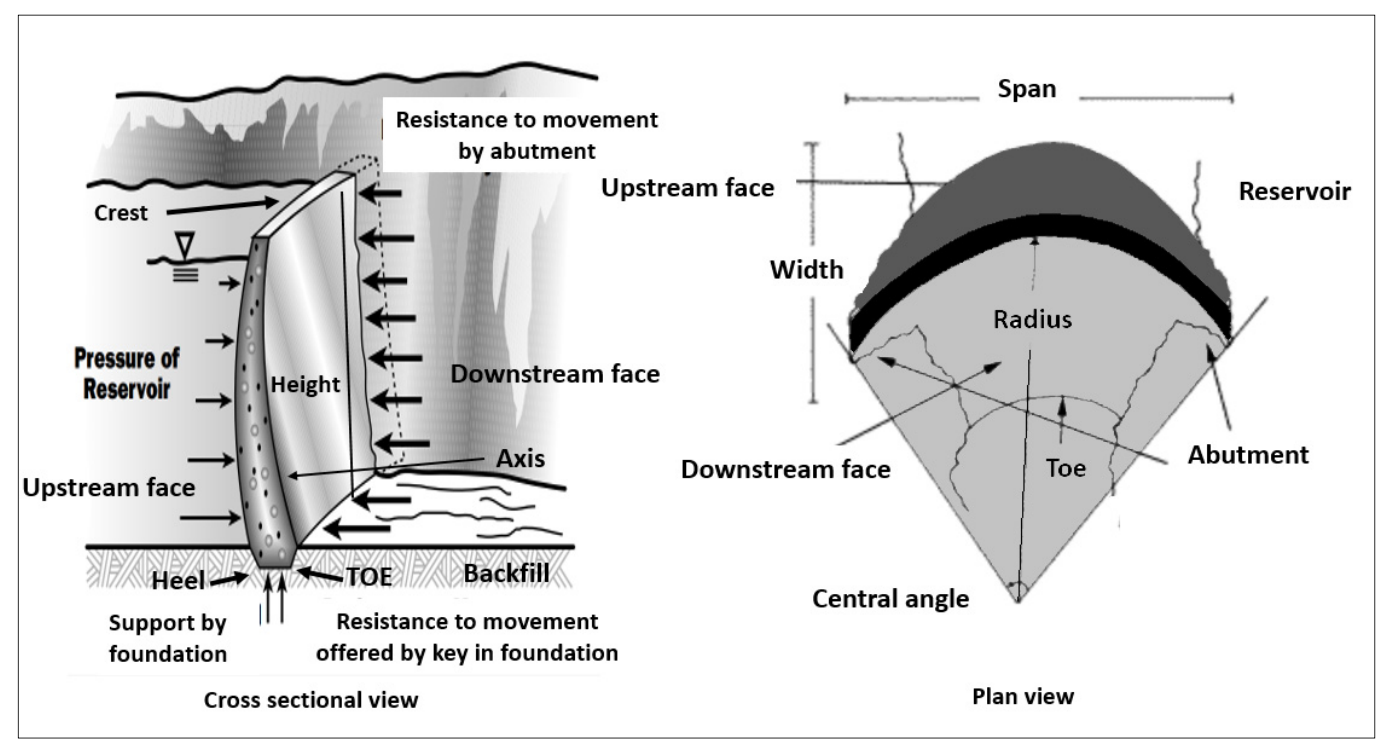

(a)

(b)

Figure 5. Arch dams: (a) cross-sectional view and (b) plan view [38].

\subsection{Classification Based on Dam Size}

There are numerous dams constructed around the world and each has unique features. When constructing a dam, various factors such as discharge, geological and hydrological conditions, terrain and river basin pre-processing information are considered which make their classification much more difficult $[39,40]$. However, many studies have considered categorizing them by size. The class of the scale can be determined by the height or storage of the dam. The height and storage of a dam are classified with respect to its potential maximum storage capacity, which is measured from dam toe of the natural streambed to the highest water storage elevation i.e., crest. The classification based on the size has been defined by many ways such as hazard potential, height, storage volumes [41-44]. To determine the size category of a dam, the highest water storage elevation must be considered as the height above the streambed, as outlined in Table 1.

Table 1. Dam classification based on dam size.

\begin{tabular}{ccc}
\hline Category & Storage $\left(\mathbf{1 0}^{\mathbf{6}} \mathbf{~ m}^{\mathbf{3}}\right)$ & Height $\mathbf{( m )}$ \\
\hline Small & $<1.23$ & $<12.19$ \\
Medium & $\geq 1.23$ and $\leq 61.67$ & $\geq 12.19$ and $\leq 30.48$ \\
Large & $\geq 61.67$ & $>30.48$ \\
\hline
\end{tabular}

\subsection{Classification Based on Construction Material Rigidity}

Dams can be classified as rigid dams when they are constructed using stiff materials such as masonry [45], steel [46], concrete [47], rubber [48], and timber [49]. Non-rigid dams are dams constructed from relatively less stiff materials and can easily be deformed when exposed to water effects and other forces. Dams built with rock or earth fill are non-rigid dams [50]; they are associated with large deformations and settlements. Sometimes, rock-fill dams are classified as semi-rigid dams because they are neither fully rigid nor fully non-rigid. 


\subsection{Classification Based on Vibration Effect}

Based on the vibration effects on dams, a new classification was required to show the vibration effect on each type of dam and to reduce this phenomenon by constructing a suitable model to analyze the danger of vibration on each type. Here, a new classification can be recognized based on the vibration effect on dams. The most commonly employed tests are forced vibration testing and ambient vibration testing [51,52].

\subsubsection{Embankment Dams (Large, Medium, Small)}

Embankment dams are classified according to the constituent materials of the dam body that can be adversely affected by vibration, dam size, and its location, as well as the acting forces [53]. It should be noted that seismic excitation consists of a broad spectrum of frequency, random, and transient in nature. The design and geometry can amplify the frequency and increase acceleration during the seismic event. However, seismic displacement and shear strain are found to be less sensitive to the vibrational changes [54]. The non-linear material behavior of the 3D geometry of the rockfill dam and asynchronous base excitation due to earthquake can affect the magnitude of 'whip-lash' effect [55].

The seismic design of these dams depends on the techniques applied, dam geometry, dynamic interaction of the fluid, and solid phases inside the dam structure. By considering acceleration and displacement, failures can be examined, and necessary modification can be done [56]. Thus, studies which focuses on the natural frequencies, modal shapes, steady-state-response, non-linearity of material, the seismic and harmonic response on embankment dam should be considered [57]. The vibration can be analyzed by making 2D or 3D models of the dam-foundation-reservoir system based on its components and the existing foundation with the reservoir, considering the dam size and location. Studying the vibration influence on dams is considered a supplement to the study of dam stability. The design standards of the dam components and the limits for variables such as stress, strain, deflection, and deformation must be known; 2D or 3D numerical model results must be compared with the measured data acquired from the dam site.

\subsubsection{Concrete Dams (Large, Medium, Small)}

These dams are classified based on their shapes (arch dam) and the connections between the parts of the dam body (gravity and buttress dams). These dams are affected by strong vibrations. To analyze the influence of vibration on these dams, knowing the constituent materials of the dam and the foundation properties is essential, so a suitable model can be constructed to determine the connections between the concrete parts of the dam body and the foundation. Hence, discrete-time Fourier transform, Wiener transform, wavelet transform, and Hilbert-Huang method can be used for static structural health monitoring $[58,59]$. The results of the model must be compared with the standard limitations of stress, strain, deflection, and deformation shape. In addition to the requirements for the dam, the location of cracks in the concrete must be determined and tested to ensure acceptability with respect to the dam location (if located within earthquake-prone zones) and the stability of the dam. The dynamic behavior of the dam should be assessed and for calibrating mathematical as well as 2D/3D models to measure damping ratio, modal shapes, resonant and seismic frequency [60].

\subsubsection{Composite Dam}

This type consists of concrete parts that mostly include the important components of the dam (the powerhouse and the spillway). This type of dam combines the characteristics of soil and concrete dams, so models must consider the existence of the powerhouse and the spillway and their influence on the operation and the different parts in the material (concrete, soil components) must be considered to produce results that most accurately reflect reality. The soil-concrete interface is affected in great depth during the seismic event with high peak crest acceleration and the dynamic reaction is also higher than static reaction [61]. Since composite dams show signs of two or more types of dams, their 
seismic behavior analysis is quite intricate. These dams tend to show different peak acceleration and amplification ratios at various dam structures. In addition to that, there is an existence of different phases among the composition of the dam [62]. Due to the unique composition of these dams, the response to the natural and operational vibrations can vary, as shown in the studies on composite dams [61,63-67].

\section{Powerhouse}

In the case of run-off-the-river dams, the potential energy in the flowing water is converted by a powerhouse into electrical energy [68]. The two factors that determine the annual potential power output of any hydropower plant are the available head and water discharge [69,70]. In the powerhouse, the potential energy of the flowing water is converted via a simple concept to a force that turns the turbine; the turning of the turbine provides the required mechanical energy to power a generator for electricity generation [12]. Figure 6 outlines the basic components of a hydropower plant.

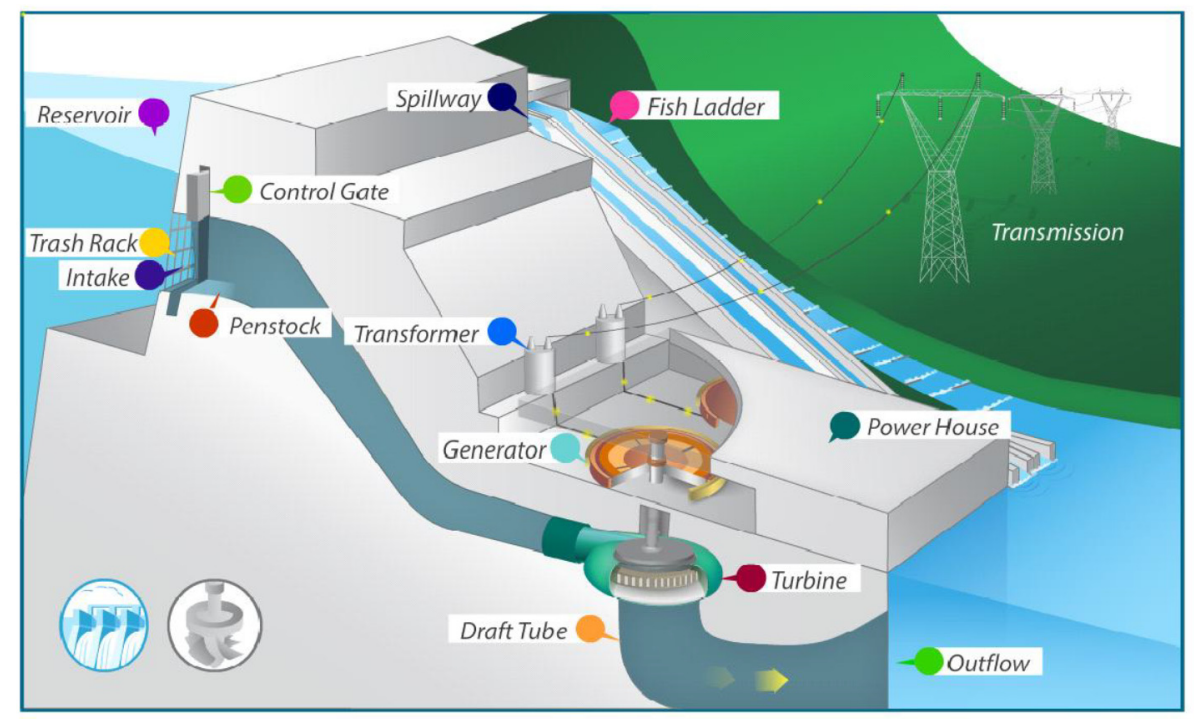

Figure 6. Central parts of a hydropower station [71].

\subsection{Powerhouse Facilities}

Conventional powerhouse plants can be classified into four types of facilities: run-of-river, storage, pumped storage plants, and micro plant $[72,73]$. Run-of-river powerhouse plants do not store river water in a reservoir but allow it to flow through the generating units as it would flow through a river. Storage plants have a reservoir to allow for more flexible adaptation to electricity demands, whereas the pumped storage plants have a reservoir but can also operate in reverse through pumping water back into the reservoir to be stored when demand is higher. The run-of-river plants must adapt to the variability of inflow conditions on generation; storage plants are not that vulnerable. The increased control of water by a storage plant results in a greater environmental impact than that caused by run-of-river plants.

\subsubsection{Run-of-River}

A run-of-river powerhouse plant transforms the water energy to electrical energy mainly from the water flow of the river (Figure 7). This type of powerhouse plant may involve some brief period of storage; however, the production of electrical energy varies depending on the local river flow conditions, which depends on precipitation and runoff quantity. Run-of-river powerhouse plants will have more viable generation profiles, especially when situated in small rivers or rivulets that experience a wide range of flow variations. In run-of-river powerhouses, river water may be diverted 
to a pipeline or channel (penstock) where it is connected to a hydraulic turbine that is joined to an electricity generator.

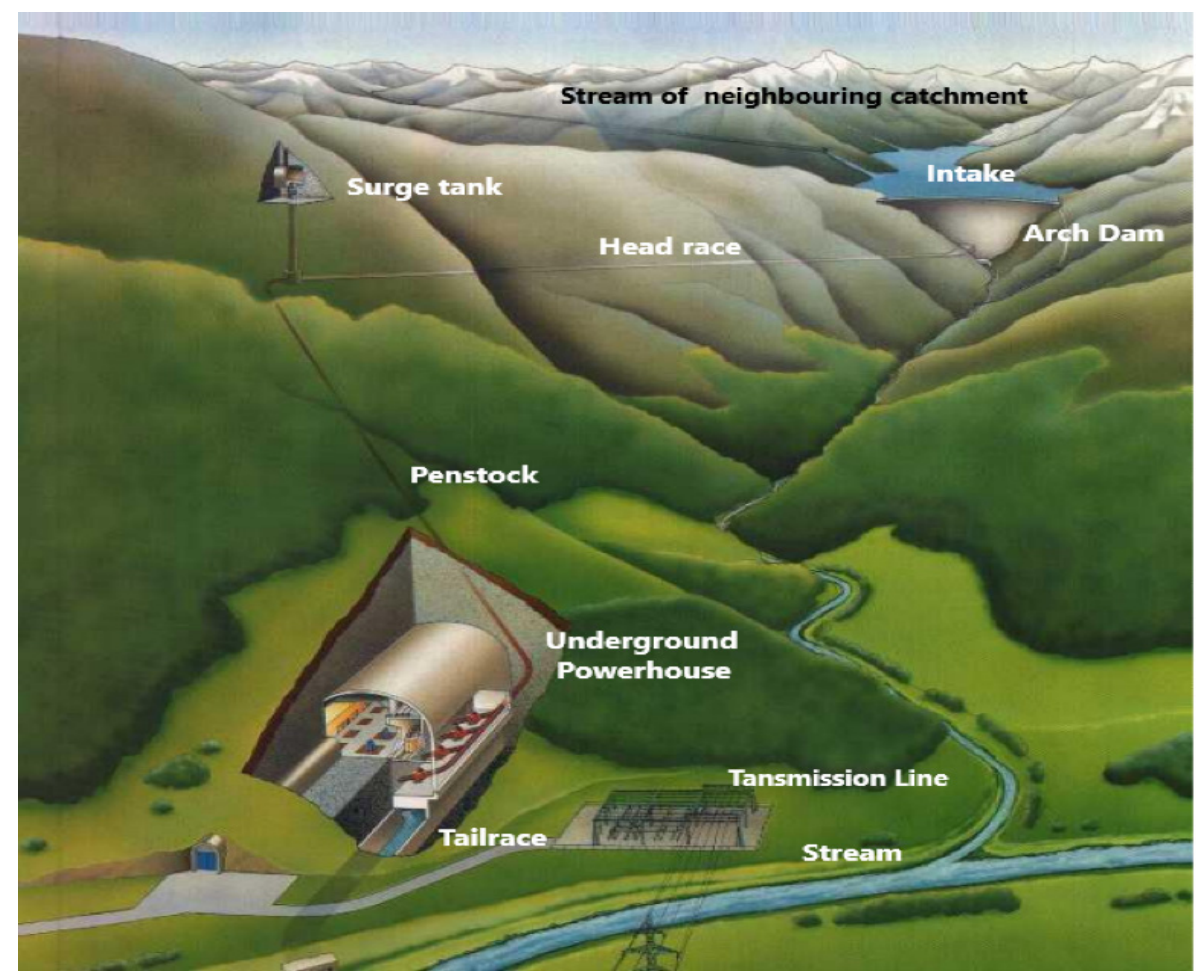

Figure 7. Storage and run-of-river powerhouse, modified from Corà [74].

\subsubsection{Storage}

Powerhouse projects with a reservoir are also defined as storage powerhouses as they can store water for later use to reduce the dependence of dam performance on the range of influx. Normally, the location of the powerhouse station is at the dam body or downstream where it is connected via channels or pipelines to the reservoir. In some cases, the stored water is also used for power generation for an alternating period of time during the peak load where unused energy can be converted to a low-cost energy, though it is true only in case of a stored facility at a higher elevation than the power house [75].

\subsubsection{Pumped Storage}

A pumped storage plant pumps water from a downstream reservoir to the reservoir instead of the storage and only is used during peak electric demand. This storage technique utilizes the gravitational potential energy of water when pumped from a low-level to high-level reservoir as in run-off-the-river dams, as shown in Figure 8. Off-peak electric power is used for running the pumps, and water discharge is reversed to generate electrical energy for the daily peak load period. 


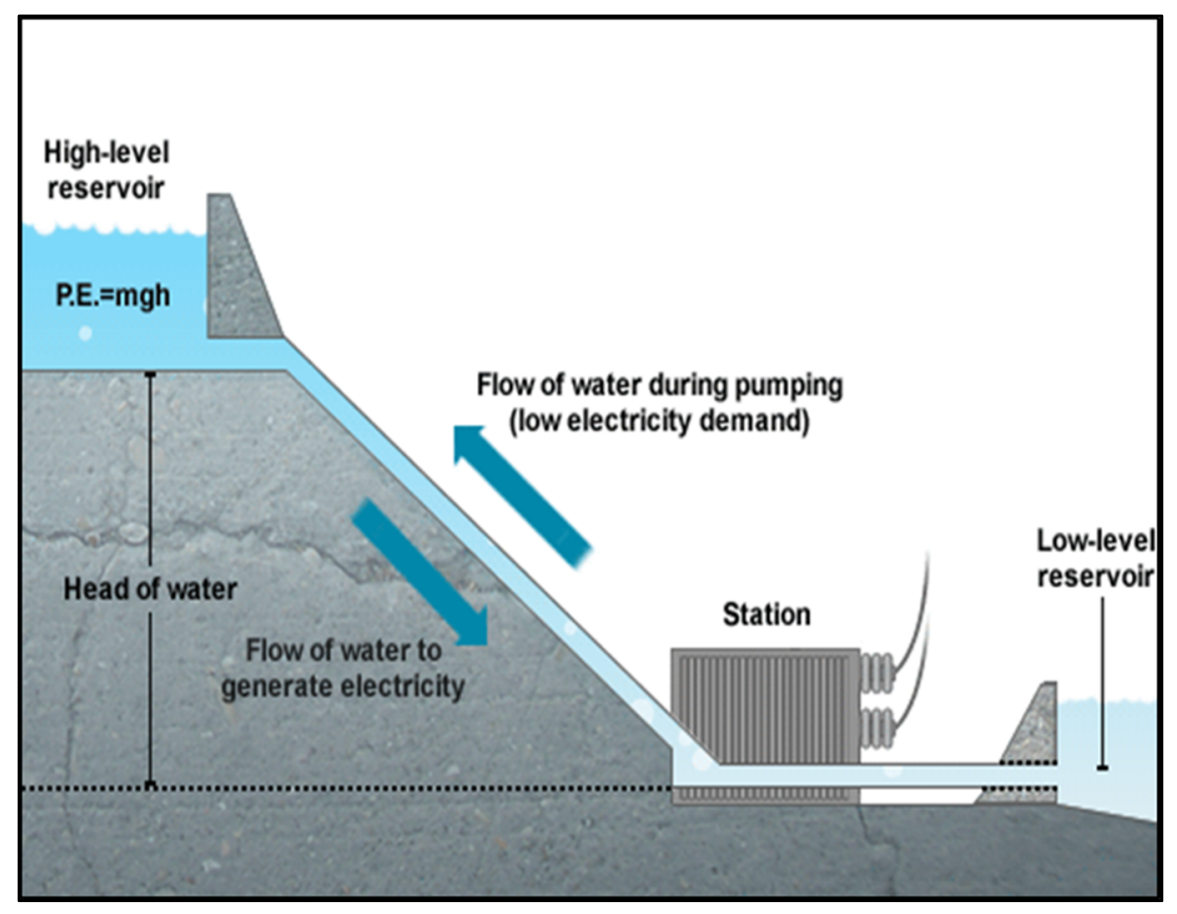

Figure 8. Pumped storage powerhouse [76]. P.E. is potential energy.

\subsubsection{Micro Plant}

The micro plant is one of the cost-effective energy technologies that mostly is considered for rural electrification in less developed countries. It is also considered as one of the environment-friendly sources of energy. The energy power capacity production is limited between ( 5 to $100 \mathrm{KW}$ ). There are different kinds of micro hydropower plants: micro Francis, micro Pelton, micro Kaplan, bulb, Pit (variation of bulb turbine), S-Type, Cross-Flow, water wheel, and Archimedes screw [77]. One of these kinds is the micro plant with a water wheel which is considered environmentally friendly and more cost-effective than those with reaction turbines. Water wheels of various types had been used in Europe and Asia for some 2000 years, mostly for milling grain [78]. Micro-hydro plants exploit sites with heads of the order of meters or few tens of meters, and discharges of a few cubic meters per second or less [73].

\subsection{Main Components of a Plant}

Most plants are dependent on dams that retain water; this water retention results in the existence of a large water reservoir that is used as storage. The storage can be a part of the dam body or constructed separately and located downstream of the dam. The essential parts of the dam must be identified as the dams' material, the form of the dam, and spillway and powerhouse locations with types and sizes, quantities, and types of turbines with inlet and outlet locations, length of penstock and draft tube, and purpose of dam construction.

\subsubsection{Intake, Penstock, and Surge Chamber}

Water delivery from the penstock to the turbine is controlled by controlling the opening and closing of the gates or intake structure which controls water movement on the upstream face of the dam or central part of the tailing dam. Normally, headrace is conducted which transports water from the river channels to the penstock constructed with the surge tank; a surge tank is used to reduce the sudden water surge, which can cause harm or increase the stress level on the turbine. 


\subsubsection{Turbines}

As the flowing water hits the blades of the turbine (connected via a shaft to the generator), the turbine rotates. With the generator, several configurations are possible (either above or next to the turbine). The most customary types of turbines used for powerhouse plants are as follows [79]:

(1) Impulse turbines: As shown in Figure 9, these turbines allow water to enter into the casing with a substantial pressure and pass through where jets of water from a nozzle at a high speed strike the symmetrically shaped blades fixed to the rotor. The kinetic power of the water is transferred via momentum to the rotating wheel [80], and the strain is transferred to the inlet and the outlet. The resulting impulse from the jet helps to rotate the turbine, hence called impulse turbine [81-84].

(2) Reaction turbines: This type of turbine takes water from upstream of the dam and transports it through the penstock under pressure where the vector sum of impulse and reactive force together strike the asymmetrical shape blades [85-87]. These turbines are constructed within the powerhouse that has been installed in different directions depending on the site topography, the head of water, and the discharge [88]. The types of reaction turbines are classified as Francis or Kaplan turbines as outlined in Figure 10.

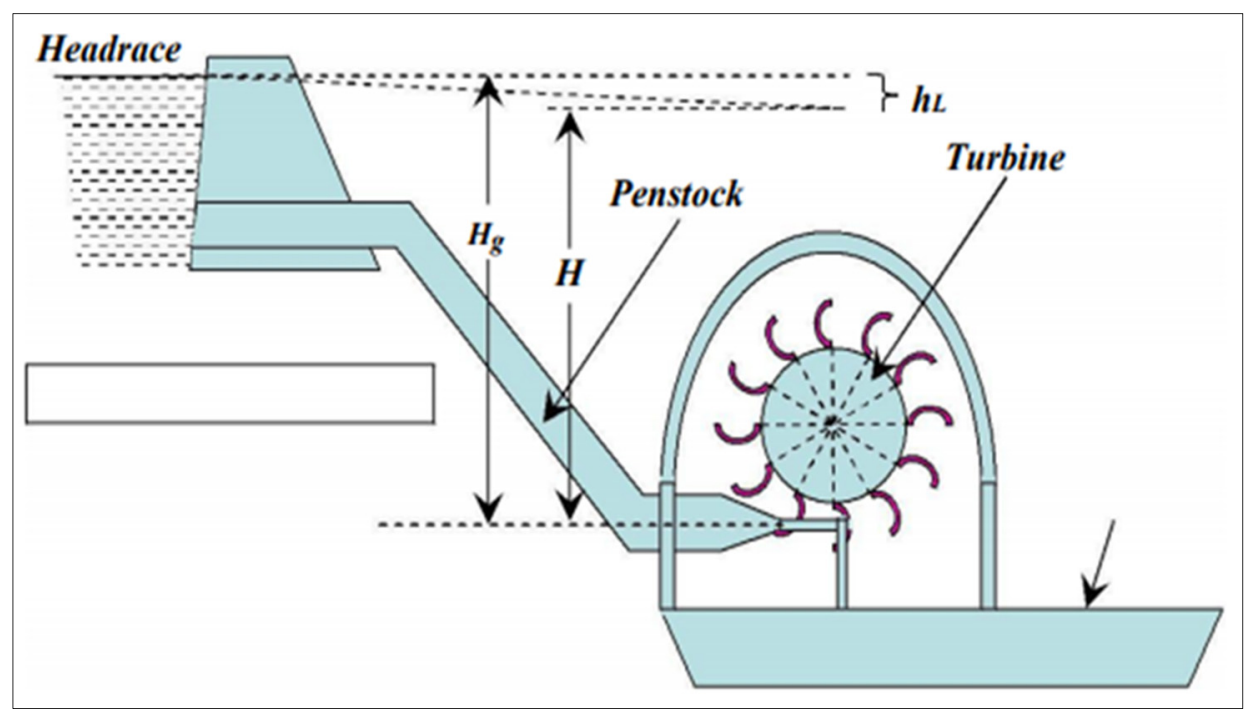

Figure 9. Impulse turbines [80].

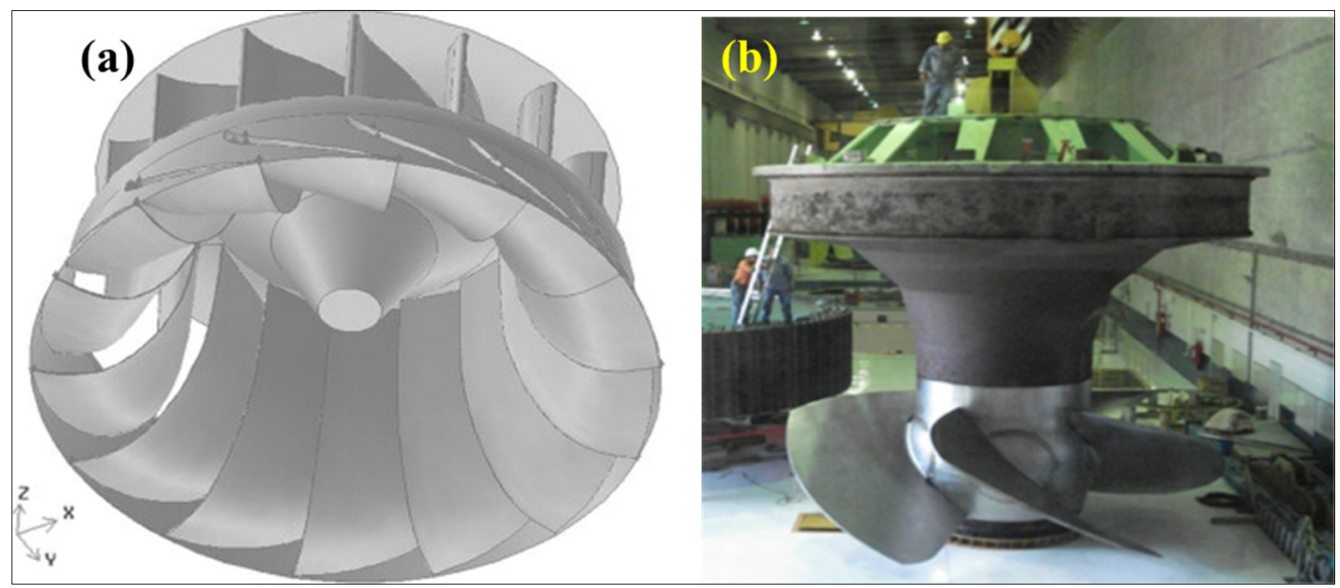

Figure 10. Illustration of two primary classes of reaction turbines: (a) Francis turbine [89] and (b) Kaplan turbine [90]. 
In a hydraulic turbine, water is channeled from the headrace through the penstock to the turbine and subsequently released into the tailrace. Then, the water-energy is converted within the turbine into the mechanical energy of the rotating shaft through the runner. The rotating shaft drives the rotor of the generator, leading to the transformation of the mechanical energy into electricity that is fed to the grid. With this arrangement, the runner can exploit all the water-energy components, including both kinetic and pressure. Several factors determine the selection of a suitable turbine configuration including the local powerhouse plant situations and their anticipated operating regimes. Kaplan and Francis turbines are generally designed to suit low and medium heads and higher discharges. The performance of a turbine is defined by these characteristics for a set of parameters.

One of the issues that affect the performance of a reaction turbine is its draft tube conduct due to the large draft tube losses at low heads and high flow rates. The major purpose of the draft tube is to ensure the recovery of some portions of the kinetic energy that leaves the runner as pressure energy. Hence, the draft tube mainly serves as a diffuser, enabling the placement of the turbine above the tail water with no head loss; it also helps redirect the flow into the tail water [91,92]. However, describing the draft tube from the perspective of fluid flow is difficult due to the interaction of numerous complex flow features. Some of these complex features are tremulousness, turbulence, separation, curvature streamline, secondary flow, spin, and vortex failure $[93,94]$.

\subsubsection{Generators, Transformers, Transmission Lines, and Outlets}

The turbine shaft is directly connected to the shaft of the generator; hence, the rotation of the turbine blades drives the rotor of the generator, leading to electrical current generation from the rotation of the magnets within the constant coil generator. The continuous rotation of the magnets provides alternating current $(\mathrm{AC})$, which will be converted by the transformer within the powerhouse into a higher voltage for onward long-distance transportation via the transmission lines. For feeding the electrical power to the distribution network, it is first transformed back to a lower voltage. The water used during power generation (called tailraces) is re-channeled back via pipelines into the river. The outlet approach may also include spillways through which water can bypass the generation system and be spilled during flooding or during times of high inflows and reservoir levels.

\section{Finite Element Modeling}

To analyze the structural vibration and seismic vibration, it is important to understand the fluid-structure interaction. For the structural safety, the dynamic behavior of the dam-foundation-reservoir system should be taken into consideration and finite element analysis can be done [95]. For examining the dynamic behavior of the structure, natural frequency, mode shapes, and damping ration should be considered which can be determined by the analytical method such as the finite element model [64]. The finite volume method (FVM) is a discretization technique which uses the integral form of the transport mass equations, momentum, energy, turbulent quantities, and species. In this method, the computational domain is first separated into a finite number of cells to which conservation laws are applied. The key step of FVM is that it ensures conservation of the integration of transport equations over the control volumes (cells), as depicted in Figure 11. For a passive scalar quantity, the general transport equation of unsteady flow is expressed in the conservative form [96]:

$$
\frac{\partial}{\partial t}(\rho \phi)+\nabla \rho \phi \vec{U}=\nabla \Gamma \nabla \phi+S_{\phi}
$$

where $\rho=$ scalar density, $t=$ time, $S=$ area of surface, $\phi$ is the dissipation term, $\nabla \Gamma$ is the heat loss by conduction.

The left side of the formula indicates the unsteady (temporal) and convective terms and the right side represents the diffusive and source terms, respectively. This is similar to the Navier-Stokes equations. By performing volume integration on both sides of the above equation and applying Green's 
divergence theorem to the volume integrals of the convective and diffusion terms, the following equation is obtained, which is the skeleton of the FV formulation:

$$
\frac{\partial}{\partial t} \int_{C V} \rho \phi d V+\int_{C S} \vec{n}(\rho \phi \vec{u}) d S=\int_{C S} \vec{n} \cdot(\Gamma \nabla \phi) d S+\int_{C V} S_{\phi} d V,
$$

where this integral form is called the non-conservation form of the governing equation.

The second term on the left-hand side and the first term on the right-hand side of the equation indicate the convective and diffusive fluxes crossing the cell control surfaces, respectively. The equation can be interpreted as the flux conservation law; therefore, conservation is satisfied by default in the FV. This characteristic of the FV makes the method an appropriate choice for fluid flow transport problems in general and especially for problems involving discontinuities like shock waves where the flow variables are not differentiable across the discontinuities, but mass, momentum, and energy are still conserved.

After obtaining the integral form of the transport equation, in the next step of $\mathrm{FV}$, the derivatives appearing in the integral equation are replaced by some approximate expressions. In this regard, traditionally, finite difference approximation based on the truncated Taylor series expansion is used, although other possibilities, such as using shape functions similar to the finite method, can also be used for this purpose. The latter creates a class of hybrid methods named finite-volume-based finite element method [97].

By performing the integration over all cells present in the computational domain, finally, a set of algebraic equations is obtained, which is nonlinear in the case of Navier-Stokes equations. To treat the nonlinear convective term in the momentum equations and obtain a linear set, usually, some lagging or linearization techniques (e.g., Newton-Raphson linearization) are employed. The resulting set of equations can be solved by well-designed efficient solvers, along with speed-up strategies like multi-grid algorithms and conjugate gradient methods $[98,99]$.

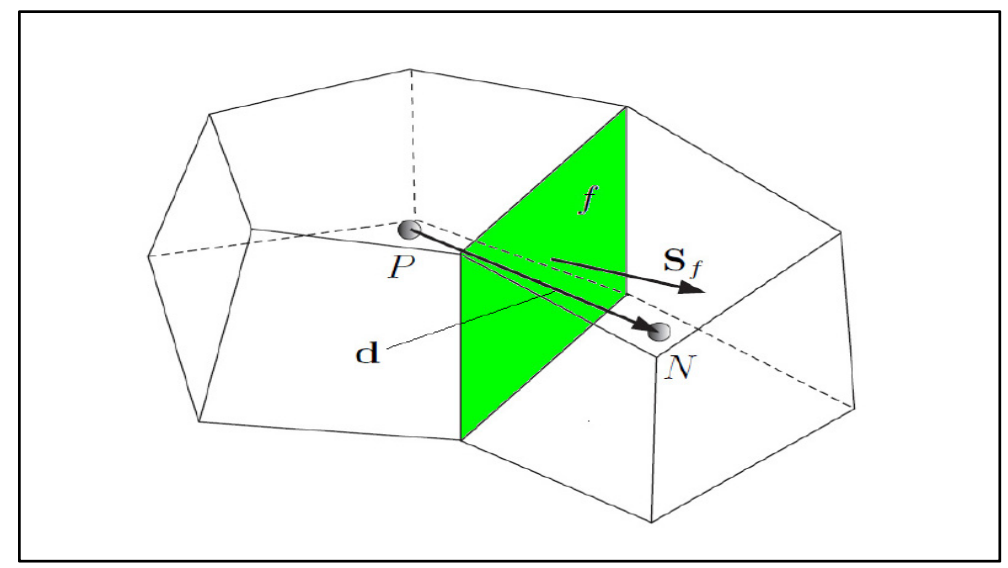

Figure 11. Control volumes in the finite volume method used for the discretization [100].

The method can be applied to the unstructured mesh and, more importantly, can ensure conservation in all computational cells and, as a result, in the whole domain. FV accuracy directly depends on the type of schemes used for the spatial and temporal discretization of the terms in the integral equations. In general, in FVM, the information on the physical quantities of the flow field (i.e., velocity, pressure, turbulent quantities, etc.) can be stored on faces, grid nodes, or centers [101,102].

\subsection{Computational Fluid Dynamics (CFD)}

CFD is a comprehensive name for all types of numerical flow analyses, including basic scientific studies as well as industrial products and process developments. The CFD codes are available in 
commercial packages and are continuously under development. In the CFD codes, the investigated flow is described by a set of partial differential equations (PDE) that generally cannot be analytically solved unless considering special circumstances; instead, they are approximated by a discretization method into a system of algebraic equations that can be solved at discrete locations in space and time. The common method for this purpose is the FVM. Other available approaches are the finite difference method (FDM), the finite element method (FEM), and a hybrid control-volume-based finite element method (CV-FEM) [103]. The main difference between the FVM and the CV-FEM method is that the pressure gradient and diffusion term in the Navier-Stokes equations are discretized with shape functions (linear) instead of the different scheme used in the latter technique. In this review, only the FVM method is described briefly due to the similarities, although both the FVM and CV-FEM methods have been used in this work (CFX-4 and CFX-5 from ANSYS-Academic engineering simulation software, are high-performance CFD software tool (Ansys Inc., Canonsburg, PA, USA)) [104,105].

In the FVM, the flow domain is discretized into a finite number of small cells, usually having hexahedral and/or tetrahedral shapes (structured and unstructured grids, respectively). The governing equations are integrated over each cell so that the nodal average quantities are conserved within each cell. A difference scheme is then used to express the surface and volume integrals in terms of the nodal values. First, the integrals are approximated, then, a difference scheme is used to express the integral approximations into nodal values. To preserve the accuracy, the order of the integral approximation must be at least the same order as the difference scheme. Usually, a second-order accuracy scheme is used to avoid numerical diffusion. Therefore, one algebraic equation is obtained for each cell in which the average cell value can be calculated from the neighboring nodes. The resulting system of the algebraic equation is finally solved with an iterative method since the equations usually are non-linear. Two types of solvers exist (segregated and coupled solvers) depending on how the pressure-velocity coupling is incorporated into the Navier-Stokes equations from the Poisson equation [106]. A segregated solver often uses a pressure-velocity correction approach to satisfy the continuity equation, whereby the pressure and velocities are solved separately. A coupled solver incorporates the pressure-velocity coupling into the continuity equation by introducing a pressure redistribution term, whereby the pressure and velocities are solved simultaneously. To avoid checkerboard oscillations, a staggered grid or a collocated grid with a Rhie-Chow interpolation scheme is normally employed in both solvers $[103,107,108]$.

\subsection{Vibration Effect on Dam Body}

The dynamic behavior of gravity dams must be evaluated by analyzing the seismic influence on the dam considering the interaction effect of the dam-reservoir-foundation system. These interactions are complicated by many assumptions and factors involved in analyzing the performance of gravity dams [109]. These factors include the foundation/dam modulus of elasticity ratio, the dam-reservoir-foundation material damping, and the bottom absorption with reservoir compressibility. For conducting this analysis, either one or a combination of theoretical analysis, field testing, and finite element (FE) modeling are normally used.

Studies have found that earthquake vibrations have various effects on dams depending on dam size, shape, body material, and location from the seismic load. These studies can be further categorized depending on the development of the programs used to analyze the effect of earthquakes on dams. Early studies used monitoring charts for various parameters, which were used to determine the seismic effect on dams [55]. The peak values of these parameters and the theoretical method (like deterministic differential equation, finite element method, smoothed particle hydrodynamics, discontinuous deformation analysis, and stochastic methods [110]) were used to evaluate the dynamic behavior of dams. 


\subsection{Earliest Dam Studies}

Gazetas and Dakoulas [55] analyzed earth-filled dams and the effects of vibration on a rock-filled dam with emphasis on the graphs that indicate the effects of vibration due to displacement, accelerations, as well as shear strain and seismic coefficients. Discussions included the changes in these parameters with changes in depth, starting from the dam crest. Lastly, a dimensionless graph was used to determine the upper limits of the parameters.

The variation in the acceleration, displacement, and strain experienced by a dam during an earthquake can be used to evaluate the maximum acceleration and predominant frequency.

Fenves and Chopra [111] provided a simplified analysis of the response process of the basic vibrational mode of concrete gravity dam systems by applying two different cases: (1) dams with rigid foundation rock supports for reservoirs in impounded water and (2) dams with unfilled reservoirs supported by flexible foundation rocks. The dam model was presented as a single degree of freedom system with clear depictions of the foundation rock flexibility terms or frequency-dependent hydrodynamic terms, the maximum deformations due to earthquakes, as well as the equivalent computable lateral forces. Bouaanani et al. [112] applied a numerical approach based on the technique developed by Fenves and Chopra [111] to calculate the effects of an earthquake. This numerical approach considered the hydrodynamic pressure that acts on the rigid gravity dams, suggesting closed-form formulas for solving the problems related to fluid-dam interaction. The effect of dam-reservoir interaction is captured by any of these hypotheses:

(1) Specific attributes of the water represent the reservoir mass added to the dam.

(2) The Eulerian approach can be used to describe the dam-reservoir interaction [113]. The employed variables for this description are (i) displacements in the dam and (ii) pressure and velocity potential in the water.

(3) The Lagrangian approach can be used to represent the dam-reservoir interaction. In this approach, the dam-reservoir pattern is expressed as a function of the displacement; some restrictions are also suggested though with the exclusion of the zero-energy mode [114-116].

\subsection{D Dam Modeling}

When considering the complexity of the geometric of dam-reservoir-foundation, most of the recent studies analyzed the seismic effect on concrete $[15,117,118]$ and embankment dams $[119,120]$; 2D numerical models for dynamic behaviors were used based on the FE method. Lotfi verified the seismic effect on gravity dams using the MAP-76 program [121] to construct a 2D FE numerical model for a pine flat dam [117]. The proposed technique was constructed by separating the model approaches overtime to find the frequency for the dam and reservoir separately. The maximum principal tensile and compressive stresses decreased by $2.2 \%$ and $1.8 \%$, respectively, by doubling the number of modes used over the initial case. Two years later, other scholars [118] created a 2D FE numerical model to analyze the seismic effect on a concrete gravity dam. The mode, shape, and hydrodynamic pressures of 20 2D FE concrete gravity dam models were analyzed and calculated using ANSYS considering the dam-reservoir-foundation interactions: (1) fixed-base dams with empty reservoirs, (2) fixed-base dams with full reservoirs, (3) rock-base dams with empty reservoirs, and (4) rock-base dams with full reservoirs. The results showed that the hydrodynamic pressure reduced using bedrock foundation modeling. Wang et al. [122] used ABAQUS software (ABAQUS Inc., Dassault Systèmes Simulia Corp, Johnston, RI, USA) to generate a 2D FE numerical model that represents a gravity dam and part of its reservoir. The open boundary condition of the higher-order doubly asymptotic was developed to capture the remaining areas of the reservoir, which was simplified as the semi-infinite part with a fixed depth. In addition, the hydrodynamic pressure at the dams' heel and the horizontal displacement of the crest under two cases of El Centro ground motion were calculated. The triangular impulse acceleration represents the development of hydrodynamic pressure evaluation in a semi-infinite reservoir of fixed depth. 
The optimal shape for concrete gravity dams, coupled with the dam-water-foundation-bed interaction, was determined using a hybrid meta-heuristic optimization method [15]. A 2D FE numerical model was proposed by using an APDL (parametric design language) program to represent the dam, reservoir, and foundation. The model considered the interaction of the dam-reservoir-foundation system according to the procedure followed by Fenves and Chopra [111]. The numerical results suggested techniques for gravity dam shape simulation and considered the dam-reservoir-foundation interaction as an important standard for safety design requirements. Miquel and Bouaanani [123] applied a 2D FE model using ADINA software (ADINA R\&D, Inc., Watertown, MA, USA) to represent a gravity dam. In their study, a new technique was proposed to investigate the earthquake effect on gravity dams by modifying the original input acceleration to obtain a new accelerogram that directly accounts for the fluid-structure interaction effect. The principal stress distribution, frequency, and crest displacement were evaluated by changing the dam dimensions to identify the dynamic behavior of the gravity dam. Mehdipour [124] analyzed a 2D FE numerical model using ANSYS software (Ansys Inc.) to determine the foundation effect on the seismic behavior of a concrete dam by considering an assumption of a rigid and fixable foundation for dam-foundation interaction [63]. The frequency, stress, hydrodynamic pressure, heal, crest, and toe displacements were estimated at the beginning $(0.005 \mathrm{~s})$ and at the end $(7.5 \mathrm{~s})$ of the time to find the change percentage of these parameters. The dam-fluid interaction was reported to increase with decreasing effective mass and vibrational frequencies of the dam.

Anastasiadis et al. [125] studied a 2D model analysis method that was implemented with respect to evaluate the mode shapes of the symmetrical areas of the high rock-filled dam body. MAP-76 [121] (Amirkabir University of Technology, Tehran, Iran), a special computer program, was applied during the study. This approach was also implemented on the dam body and the performance-matched to the direct analysis techniques. Then, the authors commended the accuracy of the method and the convergence was controlled. A 2D FE model using the FLAC2D program (Itasca Consulting Group, Inc., Minneapolis, MN, USA) was used to assess the dynamic behavior of the Renyitan earth-fill dam based on the Chi-Chi earthquake acceleration records [119]. The displacement, pore water pressure, and acceleration due to the seismic effect were evaluated to verify the stability of the dam.

The impact of the Iwate Miyagi earthquake (2008) on the Aratozawa rock-fill dam was evaluated using a 2D FE method [126]. The authors considered the decreases in the stiffness of the dam material and arching action. The results revealed a total settlement of about $37 \mathrm{~cm}$ at the top of the core. Mouyeaux et al. [127] examined the stability of the earth-fill dam by applying the stochastic FE method using Monte Carlo simulation and soil properties data. The results showed that characterizing the variability of the sliding safety factor is possible. Others applied the direct FE method to the non-linear response of the semi-unbounded dam-water-foundation system using seismic input as an effective earthquake to model the non-linear mechanisms of concrete dams [128]. Similar studies were conducted using foundation mass and earthquake input for a concrete dam in one case, and in another, radiation damping and foundation mass were used as input to design two models (free-field boundary condition and domain reduction method) based on the FE method. Both models were found to be competent and accurate for FE modeling [129,130]. Another study tested pore water pressure in an earth dam to assess the mechanical stability using a 2D random FE method with Monte Carlo simulation [131]. Sotoudeh et al. [132] evaluated the seismic behavior, demand, and capacity of concrete dams using incremental dynamic analysis with an FE model. The results showed that the exceeded probability of the limit-states curves measured at different intensities is a useful tool for probabilistic framework studies.

\subsection{D Dam Modeling}

The advancements in software development and improvements in computer speed have allowed scholars to analyze seismic effects and better understand their dynamic performance by applying realistic 3D FE models rather than 2D models [133]. Hariri-Ardebili and Mirzabozorg [134] investigated 
the effect of four different water levels and the seismic effect on an arch dam's dynamic behavior. Another study [33] developed 3D FE models for representing three types (gravity, buttress, and arch dams) of concrete dams. In both studies, the 3D boundary conditions were clearly defined for the dam-reservoir-foundation interaction system.

Watanabe et al. [135] used a vibration test on a 3D elastic model to determine the dynamic behaviors of a fill dam. The authors developed a computer code for simulating the vibration test data to recognize the fundamental modes and check the validity of the code. According to the topographical features, the effects on the dynamic behaviors of the dam, the abutment side slopes, and the bed width of the river were considered to test the extent of the fluctuation of the Eigen frequency (up to the fourth order) depending on each factor with a number of numerical traces. A dimensionless Eigen frequency and topographical features relationship diagrams were presented as the results of the code. In 2007, researchers created a 3D FE model of a rock-fill dam with a central clay core using IZIIS software (Cyril and Methodius University, Skopje, Republic of North Macedonia) for calculating the nonlinear dynamic behaviors of the dam considering the Moher-Coulomb failure criterion. The authors also evaluated the tension cut-off zones, the plastic deformations, and the stress-shear strain relationship [19]. The results showed that 3D analysis and nonlinear material treatment of the dam soils are fundamental in the evaluation of the stability of the rock-fill dams.

Dakoulas focused on concrete-faced rock-fill dams and investigated the longitudinal vibration that causes compressive stresses, causing an opening of a joint in the concrete slab panels [133]. Dakoulas used a 3D hyperbolic model to estimate dam behavior when exposed to vertical and longitudinal vibrations. During the investigation, the rocks' flexibility and the possible dynamic rock fill settlements were considered. The dynamic settlements' effect was analyzed and the responses from the upstream to downstream as well as variations of combinations were compared.

Other research examined the dynamic behavior of rock-fill and concrete dams and verified their observations via 3D and 2D model comparison [136,137]. In other studies, the model results were compared with in situ dynamic assessment data. However, the results verification via $2 \mathrm{D}$ and $3 \mathrm{D}$ simulation was not considered a valid approach. Additionally, 2D models cannot represent non-linear and 3D behavior of dams as they represent only one aspect of the dam and cannot predict modes across valley and estimate efficiently the mode shapes.

Jafari and Davoodi performed dynamic analysis using 2D and 3D models of an embankment dam in ANSYS (Ansys Inc.). The soil properties were calculated based on in situ dynamic tests. The effects of water depth, abutments, and foundation on model parameters were investigated along with the dam-foundation interaction [136]. Yilmazturk et al. [109] analyzed 2D and 3D FE numerical models that represent an RCC gravity dam by applying the EAGD-84 program (Earthquake analysis of concrete gravity dams), and the vertical stress, principal stress, maximum displacement, and frequency parameters were calculated. The 2D and 3D model results were compared to underline the calculated parameters that were used to evaluate the dynamic behaviors of the gravity dam and the dam should be tested for seismic safety assessment [109]. Albano et al. [138] constructed 2D and 3D finite-difference models using FLAC2D and FLAC3D software (Itasca Consulting Group, Inc.) to evaluate the dynamic behaviors of a bituminous concrete-faced rock fill dam constructed in Italy [138]. The dam height was $90 \mathrm{~m}$ and the embankments were built in a narrow canyon and in an area with high seismic activity. The validation of the residual displacement numerical model results with a centrifuge test performed on a small model of the dam proved the rock-fill dam to be stable and that the largest settlements occur when the reservoir is empty. Deformation was mostly located in the upper third part of the embankment.

Different degrees of seismic damage due to tension and dynamic performance on roller-compacted concrete using a quasi 3D FE model were analyzed [139]. The authors concluded that electro-mechanical impedance based on PTZ (pan-tilt-zoom) sensors (based on the perspective distortion correction method and also can increase the monitoring range) can detect the seismic damage and the model can measure the damage level. Another study explored the seismic and structural health of the Baixo 
Sabor dam and Cabril dam in Portugal and modeled them using the 3D FE method [140]. A 2D FE model was applied [141] to assess the impact of an earthquake on the Sefidrud buttress dam potential failure zone. The results suggested that dam is safe from another future MCE (maximum considered event) level earthquake (MCE is the expected event for a specific area where large structures have been designed such as dams and structural breakdown of the dam can lead to calamitous chain of events), despite the seepage flow increase in fractures as the there is enough permissible expansion area between the cracks resisting the damage. A study on a concrete gravity dam on King's River, California, used seismic input excitation for constructing a model based on Bayesian non-linear FE and an advanced non-linear Bayesian filtering method known as the unscented Kalman filter to present the plain concrete behavior as a 3D non-smooth multi-surface concrete model [142].

\subsection{The Vibration of Turbines and Powerhouse}

To produce low-cost hydroelectric power in dams, it is essential to focus on the powerhouses. Hence, the key to finding the effect of turbines operating in the dam body is to detect the hydraulic characteristics in the reaction turbines [143].

The hydraulic characteristics of Kaplan and Francis turbine units [143] serve as the main engine of a powerhouse. Kaplan and Francis turbines, which are classified as reaction turbines, are difficult to use under part-load operation due to pressure oscillation [144-146]. Studies on this topic have presented solutions to the cavitation problem in draft tubes, the vibration effect in powerhouses caused by the operating turbine, the maximization of power generation, and the generation of low-cost power $[85,89]$. Fluid computational tools have rapidly developed in the field of CFD [147-150], enabling robust and reliable analysis of the flow pattern inside the turbine structure.

Zhang et al. [151] proposed a mathematical model of the hydraulic influence generated under several load conditions in the draft tube vortex from a theoretical analysis perspective. The study proceeded by inserting the increasing load transition process into the hydropower vibration model that was previously established; this non-stable operation condition was also studied in terms of its dynamic characteristics. The authors observed that the displacement intensification can be several times greater than the vibration in the vertical direction if the model system is operated stably. Reasonable and reliable models and methods were provided for dynamic response exploration, fault diagnosis, and stability investigation for the structures in the hydropower and generating units. Another study analyzed the vibration characteristics and gyroscopic effects of the hydro-turbine generator by applying a non-linear mathematical model [152]. The model was able to accurately calculate the influence of vibration on a turbine. A detailed study [153] was completed on vibrational problems due to the imbalance within the system. The authors concluded that a safe location exists with different bearing properties of the turbine rotor on the shaft when tested at different location from left to right of the shaft.

\section{Turbine Analysis}

\subsection{Francis Turbine Modeling}

Several studies applied the above-mentioned tools for flow behavior simulation in turbine draft tubes and for inspecting critical conditions, such as the vibration and vortex rope [146,154]. Pressure pulsation and the cavitation phenomenon have been studied in Francis hydraulic turbine units; the latter creating an issue in the functionality of the turbines has been discussed $[155,156]$.

A 3D numerical model was built [157] for the prediction of the vortex rope in the draft tube of a Francis turbine unit based on two numerical flow analyses (with and without the effects of cavitation). Similarly, the cavitation turbulent flow under partial load operation was numerically studied in a Francis turbine using the $\mathrm{k}-\omega$ (k-omega model which predicts well near boundaries) shear stress transport turbulence model in the Reynolds-averaged Navier-Stokes equations [22]. Qian et al. [158] simulated 3D multiphase flows to estimate the pulsation pressure in the runner front, draft tube, guide vanes, and spiral casing using fast Fourier transform of a Francis turbine. Another study [159] focused 
on the pressure fluctuations and their hydrodynamic effects within the draft tube. Also investigated, via the simulation and analysis of the transient state turbulence flow in a Francis tube using 3D analysis, was the basis for the rotor-stator interaction under partial load operation. The flow through a Francis turbine (vertical) was analyzed under different loads using the 3D Navier-Stokes CFD solver ANSYS CFX (Ansys Inc.). Luna-Ramírez et al. [160] calculated the pressure on the blades of a 200 MW Francis hydraulic turbine; the aim was to use CFD to locate the failure on the surface of the blade. Several studies have analyzed the Francis turbine, focusing more on its computational features [89,161-163].

The pressure pulsation of flow via the duct of a medium-scale hydrodynamic bench with Francis turbine was analyzed [164]. The authors measured the characteristics of various pulsation regimes of the Francis turbine. The flow pattern in the Frances turbine was analyzed with the help of high-speed filming, and the effect of flow pattern on the flow duct was demonstrated by examining the frequency and intensity of pressure pulsations. Luo et al. [165] analyzed the unsteady multiphase flow in a Francis turbine and the pressure oscillations in part-load operation. Pressure oscillation was alleviated using air admission in different cavitation cases to improve numerical accuracy. The results showed that the pressure oscillation cannot be depressed completely in the vaneless area due to rotor-stator interaction. Sakamoto et al. [166] predicted the dynamic characteristics of the Francis turbine to improve the numerical flow accuracy. The authors compared the CFD-simulated velocity fields with the LDV-measured velocity in the draft tube cone. The modeling was performed for six discharge values, four partial loads $(40 \%, 60 \%, 80 \%$, and $90 \%)$ of the discharge with the best efficiency point, and one full load of $110 \%$. The steady Reynolds-averaged Navier-Stokes (RANS) was simulated by performing the ANSYS CFX solver (Ansys Inc.). Trivedi et al. [167] examined the effect of unstable pressure fluctuations during steady-state operation in a Francis turbine model. The correlation of pressure fluctuations between the rotating and stationary components in the turbine unit was the focus. The pressure data were acquired by installing four, one, and two pressure sensors in the runner, the vaneless space, and the draft tube, respectively. The results demonstrated that the pressure data from the vaneless space and the draft tube accurately represent the pattern of the pressure changes generated in the runner. Yu et al. [168] numerically simulated a Francis turbine with vortex-control grooves based on the partially averaged Navier-Stokes method. The pattern of the cavitation rope and the pressure changes under varying operation conditions were investigated based on the outcomes of the calculation.

Pasche et al. [169] investigated the initiation and propagation of synchronous pressure waves in Francis turbines. They exploited the energy factor of an azimuthal-temporal Fourier decomposition to model the 3D numerical flow within the draft tube, which was slightly distressed at the wall and also identified the synchronous pressure source and the implication region. Trivedi and Dahlhaug [170] focused on the unsteady flow that causes fluctuations in the high energy stochastic generated in a highly skewed blade cascade. At the runaway speed where the tangential velocity is dangerously high with significant energy loss, which can affect the turbine service life, a compound turbine structure was operated in that region. The time-dependent inception of the vertical rings was also experimentally and numerically measured in the blade cascade. From the results, accurate pressure pulsations (unsteady), associated with the wave propagation and reflection, were recorded. Cheng et al. [171] investigated the strong spinning current which exists between the runner and draft tube of Francis turbine at a part load condition; this flow can cause a vortex rope within the draft tube. The draft tube flow field was simulated via a VLES (Very-Large Eddy Simulation) simulation, which is built on the theory of filtration of large part of fluctuating turbulence and k-epsilon model, as compared with three turbulence models RANS (Reynolds-averaged Navier-Stokes) where increased filter width beyond the largest length scale leads to the RANS standard prediction, LES (Large Eddy Simulation) where limited filter width scale leads to the LES standard prediction, and a hybrid RANS-LES technique. The outcome showed the capability of the VLES model to successfully decrease the eddy viscosity and velocity in the vortex rope, thereby reducing the pressure and prolonging the rope compared to the other models. 


\subsection{Kaplan Turbine Modeling}

The focus of the other studies were Kaplan hydraulic turbine units with respect to the pressure pulsation within the units and the methods to reduce the cavitation phenomenon problem. Ko and Kurosawa [172] evaluated the cavitation performance at a specific speed for a 400 MW Kaplan turbine. They used a finite volume method in conjunction with the Reynolds stress model to explain the Reynolds-averaged Navier-Stokes equations. The collapse and propagation of cavitation bubbles were modeled using the modified Rayleigh-Plesset equation. Javadi and Nilsson depended on the renormalization group $\mathrm{k}-\varepsilon$ (k-epsilon model which predicts well far from the boundary) turbulence model combined with the RANS equations to analyze the unsteady turbulent flow in a U9 Kaplan turbine model [173]. Analyses were performed on the fluctuation of pressure in the draft tube, unsteady flow behavior, and cohesive flow structures. Another investigation was conducted on the runner outlet flow of a Francis turbine model using a two-component particle image velocimetry system [174]. The findings proposed a particular shape to provide suitable optical access across the draft tube elbow. The characteristics of the flow pattern in a Francis turbine runner with a small opening valve using the RANS equations and the continuity equation were inspected [175]. The 3D unsteady turbulence flow throughout the entire passage of the turbine was simulated numerically based on the $k-\varepsilon$ two-equation turbulence model using the CFD software ANSYS Fluent (Ansys Inc.). The findings demonstrated a low-pressure zone around the blades of the runner when the valve was closed, and the velocity increased throughout the runner area. The effect of hydraulic instabilities on increasing the service life of Francis and Kaplan turbines was determined [143]. Caishui built a mathematical model to study the distribution of pressure within the flow behavior in the powerhouse of a powerhouse station [176]. The pressure and velocity distribution pattern were determined under three operating conditions: one-unit load, two-unit load, and full-load rejection applying CFD. The results outlined a good flow pattern at the inlet with an even fluctuation in water level. The extensive state-of-the-art studies on the pressure pulsation in the draft tube of Kaplan and Francis turbines applied the same methods and analyses but use different models. Several researchers suggested changes in the turbine design to reduce the cavitation phenomenon and proliferate turbine efficiency.

In many studies, Kaplan turbines are used as a reference for the hydraulic characteristics of the other considered turbines. A sensor fish at the Ice Harbor dam was used [176] to characterize the hydraulics at various conditions. This critical understanding of the performance level of the Kaplan turbine can help to advance design and operational improvement. An investigation was conducted [177] of the influence of the blade dynamics overflow rate, efficiency, and power, which was only used in past tests in Kaplan turbine models since it is assumed that runner blades normally exhibit an optimum efficiency relationship. However, this is not the case for transient responses. The results showed that the presented model based on the speed control response is capable of improving the precision of the turbines in isolated operations. A computational prediction of the initiation and propagation of cavitation in a five-blade Kaplan turbine was presented using barotropic state law and k- $\omega$ SST (Shear Stress Transport) turbulence model, which is a modified version of a standard k-omega model used for combining both the models (omega and epsilon) using blending function and altering the eddy viscosity formula. The best result was obtained by applying constant total pressure on the inlet and simultaneously predicting the torque and efficiency evolution with numerical cavitation structures to improve the overall performance [178].

Kim et al. [179] investigated the tip flow clearance features by considering a transient fast Fourier transform (FFT) analysis for a Kaplan turbine unit. The turbine unit performance with tip clearance gaps was investigated using CFD at different operating conditions. Increases in tip clearance were found to decrease efficiency due to unsteady flow. Iovănel et al. [180] investigated the flow through the Kaplan turbine model during transient operation. The authors used time step sensitivity analysis to determine the optimum discretization time and studied where the effects of the runner blades' pressure pulsations at different inlet boundary conditions on the numerical simulation accuracy. The discharge 
variation during the guide vane was found to cause turbine head overestimation compared with the experimental loss values.

\section{Main Related Dam-Hydropower Plant Problems}

\subsection{Cavitation in the Draft Tube}

Many researchers studied different solutions to the cavitation problem in the draft tube, vibration effect in the powerhouse due to the turbine operation in order to maximize the power generation. The effects can be divided into fixed, travelling, and vibrational types [181]. More advanced classifications are sheet, bubble, cloud, propulsor-hull vortex, and propeller vortex [182]. Some of these studies are outlined below.

The pressure pulsation in the Francis hydraulic turbine units has been studied by several researchers, coupled with discussions on the cavitation phenomena problem. Qian et al. [158] presented a simulation of a 3D multiphase flow in a Francis turbine; they aimed at estimating the pressure pulsation using Fourier transform (FT) in the spiral case, draft tube, a front of the runner, and guide vanes. They found that pressure distribution and frequency change with and without air admission, and the effect of air admission decreased the low-frequency pressure pulsation and increased blade frequency.

Lipej et al. [183] numerically predicted the amplitude of pressure pulsation for different Francis turbine draft tube operating systems. They also numerically predicted the vortex appearance during the design phase. The pressure pulsation amplitude was found to differ for each operating system; hence, the research primarily aimed to numerically predict pressure pulsation amplitude against different guide vane openings and to compare the predicted and experimental results. ANSYS-CFX computer code was used to model the numerical flow analysis of a complete Francis turbine. Jošt and Lipej [157] created a 3D numerical model that represents a Francis turbine unit to present the vortex rope prediction in the draft tube using numerical flow analysis and ANSYS-CFX (Ansys Inc.). The size of the time step was examined using LES, $\omega$-RSM ( $\omega$ Reynolds Stress Model), and SAS-SST turbulent models with defined grid density and domain configurations. Two analyses were performed: with and without cavitation influence. The frequency results showed that the SAS-SST and RSM models were less accurate for cavitation effect analysis, whereas no difference was found in the accuracy when the cavitation effect was ignored in the LES, $\omega$-RSM, and SAS-SST turbulent model analysis [184].

The cavitation turbulent flow in a Francis turbine was numerically investigated by Zhang and Zhang [185] using Open FOAM (Open-Source Field Operation and Manipulation-is a numerical solver used for continuum mechanics problems such as CFD problems developed by OpenCFD Ltd., England) code at partial load operation and the k- $\omega$ SST turbulence model. The authors applied the RANS equations for the evaluation. The components of the turbine unit include the runner, the spiral casing, the draft tube with a tetrahedral-shaped 3D mesh system, and the guide vanes. The study also introduced a finite rate mass transfer model and mixed assumptions, and a finite volume method was used to solve the mixed model equations. From the simulation results, the cavitation flow in a high-head Francis turbine was perfectly predicted. The hydrodynamic effects of fluctuations in pressure within a draft tube due to rotor-stator interaction at partial load operation were studied [159]. The pressure fluctuation was simulated via a $3 \mathrm{D}$ transient state turbulence flow simulation analysis in the flow of a Francis turbine at a specific speed (203.1 rpm) with an installed capacity of $70 \mathrm{KW}$. The commercial 3D Navier-Stokes CFD solver ANSYS-CFX (Ansys Inc.) was used to analyze the flow through a vertical Francis turbine in its location with $72 \%$ partial load and $100 \%$ maximum load. The turbine unit included a spiral case with 16 guide vanes, 13 blade runners, 8 stay vanes, and a draft tube. The variation in the pressure distribution and velocity vector profile with time was the basis for calculating the turbine's hydraulic performance and stability.

Several trials have been conducted to analyze the cavitation phenomenon in Francis turbines at low head under different operating settings with variable suction heads. The results showed that the cavitation rate, the magnitude of pressure pulsation, and performance loss increase with increasing 
suction head. Hydraulic turbines and types of cavitation have been described [128,129]; numerical and analytical research with theoretical studies on cavitation phenomena in hydraulic turbines have been extensively reported. Sufficient predictions for cavitation have been provided via numerical methods. Verifying the numerical results via detection methods is important to determine the vital and hazardous cavitation shapes and intensities, as well as to determine the areas where the local pressure is below the water vapor pressure and to identify the area where static pressure begins to grow and collapse. Others [186] simulated and investigated the cavitation turbulent current in a Francis turbine unit using a CFX solver; the analysis depended on the shear stress transport (SST) turbulence model, whereas another analysis of the same phenomenon was studied by Gohil and Saini [187] depending on the Rayleigh-Plesset mass transfer model. A study revealed that the $\Omega$ method can be used to successfully capture vortex structure in the cavitating flow of Francis turbines [188]. The Zwart-Gerber-Belamri (ZGB) cavitation model simulation was implemented for the overload condition in a Francis turbine [189]. The authors successfully analyzed the different development stages of cavitation and their initiation under different overload conditions, including the mass flow gain factor, cavitation compliance, and wave speed. A calculation course for improving the mixed turbine impeller using CFD was proposed [190] for analysis of the cavitation characteristic of the impeller inlet flow for hydraulic machinery. From the result, blade reshaping was found to significantly improve the impeller inlet flow performance and cavitation.

\subsection{Hydraulic Turbine Structure Design}

Favrel et al. [174] used a two-component particle image velocimetry system to evaluate the flow field through the runner outlet of a Francis turbine model. The suitable shape that will provide suitable optical access across the draft tube elbow was also designed. The model was executed based on a discharge value of $55 \%$ to $81 \%$ of the best efficiency point. The vortex parameter evaluation with the discharge was calculated based on the initial phase-averaged velocity fields. The analysis results showed that the vortex trajectory expansion occurs due to a simultaneous increase in the frequency and excitation. Mo et al. [175] considered the flow pattern characteristics around a Francis turbine runner using the continuity and RANS equations. The findings showed a low-pressure increase around the blades of the runner when the valve was closed and a velocity increase over the runner area. The 3D unsteady turbulence flow through the entire turbine was numerically simulated. The simulation used the CFD software ANSYS-FLUENT (Ansys Inc.) based on the $k-\varepsilon$ two-equation turbulence model. Luna-Ramírez et al. [160] focused on the determination of the pressure on a Francis hydraulic turbine blade to establish the failure on the surface of the blade using CFD. The stress distribution in the turbine runner was calculated using the FE method under many operating conditions. The results showed the level of stress created in the joints between the results of the crown development of cracks on the blades. Pennacchi et al. [143] studied the effects of hydraulic instabilities on increasing the life of Francis and Kaplan turbines by developing a model that included the experimental data from a full-scale Kaplan turbine unit deployed in a real power plant. The model analyzed the effect of the vibration on changing the selected node locations in the shaft of the turbine in two directions, showing the changes in pressure and frequency in different cases of flow.

The method for reducing the formation of vortex rope and minimizing the corresponding pressure fluctuations in the draft tubes of Francis turbines was improved [191]. The improvement occurred due to using a baffle to prevent the emergence of a swirling flow from the draft tube in a Francis turbine runner. Attention was focused on three flow rates with partial load operating conditions at the rated water head. Four baffles were employed in the draft tube and the vortex rope was explained using CFD. The pressure pulsation capacity of the draft tube after alteration with the four baffles was about 0.42 times that in an unaltered draft tube. From the results, the flow's circumcisional velocity in the draft tube was reduced using the baffles, thereby preventing the progression of fierce swirling flow. An efficiency increases of about $3 \%$ was measured in the turbine at the examined partial loading point. 
Jia et al. [192] investigated a Francis turbine with $200 \mathrm{~m}$ head; the authors designed the splitter blades to reduce cavitation and fluctuations in high-amplitude pressure. The outcome of the evaluation showed that the splitter blades improved the turbine efficiency by $2 \%$ and reduced the pressure wavering in the vaneless space during high head operating situations.

Nishi et al. [193] assessed the improved performance of the redesigned runner of a turbine using unformalized axial flow velocity. After examination, the optimizer runner was found to experience fewer losses due to the tip leakage vortex and the vortex near the hub of the blade, which improved the performance and efficiency of the turbine. Similarly, the maximum efficiency of the turbine was found to increase after predicting the axial turbines' hydraulic performance via CFD. The authors designed a new siphon turbine based on the original distributor and runner, which led to the best design with a bell-shape distributor, four guide vanes, and the highest power output at the lowest head [194]. Modification of the runner using grooves can reduce vortex rope eccentricity and increase the vortex pressure, ultimately increasing the turbine efficiency [195]. In another study, the stability power output of hydro-turbines, which included energy losses, sensitivity analysis, and distribution features of the losses with an elevated guide vane, was considered. Such detailed analysis helped optimize the working and control of the hydraulic turbine governing system (HTGS) [196].

Various designs have been proposed to enhance the hydro-turbine efficiency; for instance, Piraisoodi et al. [197] designed a multi-objective robust fuzzy fractional-order proportional integral derivative controller plan for non-linear HTGS by implementing evolutionary computation; Guo and Guo [198] designed a non-linear HTGS by applying feedback linearization by accomplishing sliding mode control type design; and Ouadday et al. [199] designed a dual-core composite sandwich panel for hydraulic turbines, tested the panel via numerical simulation, and applied a synergistic governing controller for non-linear HTGS.

\subsection{Powerhouse Vibration Analysis}

The distribution of pressure in the pattern of flow within a powerhouse was studied by using the fluid dynamics method, Hou Caishui [200] presented a mathematical model for finding the pressure pattern distribution and velocity distribution in a specific powerhouse under various rejection conditions such as one-unit load, two-unit load, and full load. The flow pattern stabilized with regular water level fluctuation at the inlet. Wel and Zhang developed a 3D numerical model using ANSYS software for a powerhouse body [201]. The aim of this model was to determine the pressure, acceleration, stress, and strain within the body of the powerhouse, and the frequency inside the powerhouse. The results indicated that the statically and dynamic disturbances of the hydraulic turbine blades result in the generation of most of the vibrations.

Castelli et al. [202] studied the dynamic response of the Lentini earth dam in Sicily after the occurrence of the Santa Lucia earthquake and compared it with free-field 1D PLAXIS (plane strain and axial symmetry) simulation. Lian et al. [203] studied the underground powerhouse of a hydropower station on the Yalong River in China using field structural vibration tests. They simplified the mechanical models and theoretically interpreted the transmission mechanism. The testing conditions for analysis were represented by another study using an FE model, and the results showed the propagation of the longitude-river vibration and vertical vibration was less than that of lateral-river vibration. The vibration transmission caused by the hydraulic generators' rotation was equivalent to that of the vibrations caused by the fluctuation of the low-frequency tail [203].

Dynamic loads of turbines and generators are responsible for the creation of vibration in hydropower, along with the natural causes like earthquakes and floods. Ma et al. [204] applied the energy flow FE method to study vibration transmissibility of the powerhouse and found that a structural joint filter and closed-cell foam help to reduce vibration transmissibility. Similarly, Jing et al. [205] searched for possible improvements in the dynamic characteristics of underground powerhouses and optimization of anti-vibration design. They reported improvements in the frequency and reduced amplitude of the vibration source with a better structural stiffness of the outer concrete structure of 
the spiral case. Some case studies have been conducted on the possible seismic damage to structures, such as the Yingxiuwan underground powerhouse in China using the dynamic numerical simulation method and Brežice dam in Slovenia using a laser Doppler Vibrometer [206] and FE analysis. FE analysis has been used to examine the vibrational characteristics on the spiral case structure of the Ahai Hydropower Station, where the semi-cushion spiral structure was found to be safe [203,207-209].

\section{State-of-the-Art Assessment and Evaluation}

The current review research was performed to help improving the current understanding of the consequences of the operation strategies imposed on the energy market, which tend to increase load variations, which in turn affect the lifespan of hydropower plant equipment. Hence, we debated several aspects of the topics related to hydraulic engineering, mechanical turbine engineering, and structural safety and sustainability.

The use of hydropower to generate clean energy has produced concerns over the effects of vibrations from powerhouse operation on the dam's structure. Experts from different fields have studied the issue to reduce the influence of vibration on dams and increase their stability. Understanding the vibration effect on dam bodies has mainly been the focus of studies in the field of civil engineering [14,111,119-122,136-139,141]. Mechanical engineering researchers have focused on the vibration effect on turbines [89,146,160-166,175,177-179,187].

Although dams have been classified into different types based on their function, form, size, and selection of construction material, a new classification system must be developed that indicates the vibration effect on each type of dam. New studies must be conducted that introduce the dam types, powerhouses, and turbines that are subject to vibration in combinations, in addition to the effect of these different types of dams, powerhouses, and turbines on each other. Until now, no studies have comprehensively connected the effect of vibration with turbine operation within the powerhouse in the dam body. Proposed studies should focus on constructing a suitable model to analyze the hazard posed by vibration on each type and how to reduce its effects on the dam structure. More interests should be paid to embankment dams because most dam failure incidents are recorded for this type of dam as it is most likely get affected by soil erosion, seepage, structural failure, and catastrophic failures [210-212].

The most common approach to test the efficiency of the turbines is through prototype design. However, real-time models and their performance cannot be tested with more accuracy using a prototype. To increase the predictability of machine performance, high accuracy techniques must be developed that consider various measurements of machine while simultaneously consider the dam structure, river management, and situations that can lead to dam failure.

When considering the chances of failure due to hydrological, seismic, and operation reasons, as well as extreme failures of the dam structure leading to the damage of the structure, mechanical features such as turbines and other associated devices for power generation can be considerably affected. Figure 12 lists all types of possible failures, their effects on the dam structure, affected components, and most affected area due to the failure. Figure 12 summarizes the cause and effect so that future work can focus on mitigating or solving these issues, since these events can cause monetary loss and loss of life.

Real-life failures and accidents are one method to learn about the possible failures; thus, potential failure mode analysis is essential for engineers, designers, and planners to identify risks and plan risk management policies $[213,214]$. During analysis, correctly categorizing the risk level of hazards is challenging, and analyzing complex failures and their sources is difficult, with external factors including culture, policies, political considerations, and belief and practices. To overcome this issue, it is important to critically assess the information and to seek reviews from experts and other experienced and qualified people who can better judge the design structure, maintenance, and failures [215]. Structural modifications can significantly decrease operational and other sudden failures, including better-planned buttresses, slope design, and installation of proper detection equipment. Advanced 
simulations can be used to recognize critical modes of undrained behavior (impoundment water-level projections, seasonal constraints on the dam and onsite construction, water balance), and, along with experience and experts, appropriate decisions can be made with better filter designs and feasibility analyses [216].

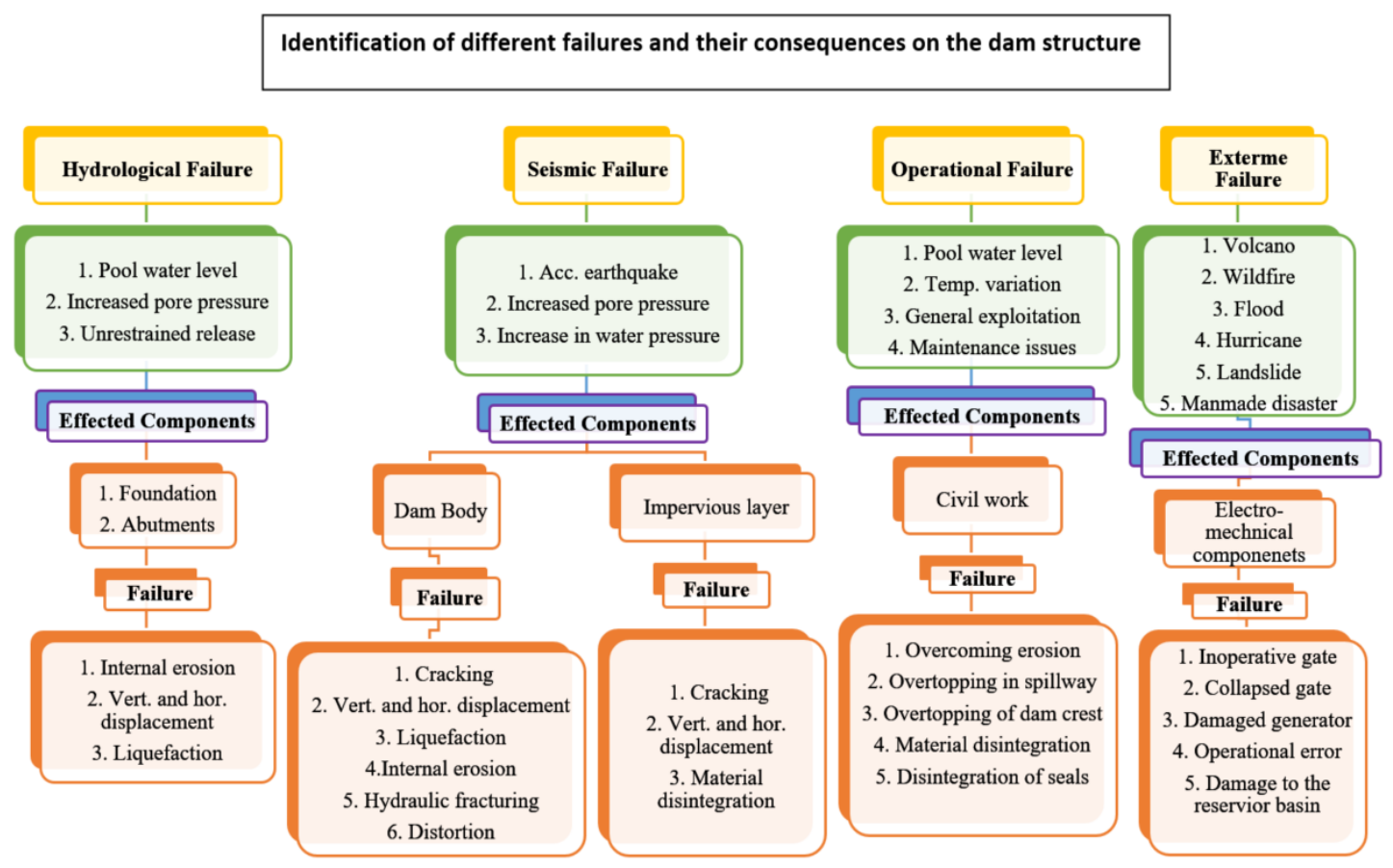

Figure 12. The distribution of the major failures and the resulting effect on the dam structure.

Our review indicates that further studies should be conducted considering the dam classification based on materials, size, rigidity, and vibrational effect as one parameter, in addition to considering the location of the structure for the lowest chance of failure for the specific dam classification. To achieve this outcome and perfect dam design, more case studies and accurate data analysis are required. Data from turbines installed in hydro-dams should be highly accurate and measured under various operational conditions and with all possible types of turbine models. These data will help to reduce extrapolation deviation and energy losses.

Some studies were completed using two-dimensional numerical models to simulate the dynamic behavior of dam bodies [15-17]. However, three-dimensional numerical models are more accurate [18,19]. Assessments based on 3D analysis, therefore, are highly recommended. Hence, selected dams, including the dynamic characteristics of embankment dams, and the reaction of turbine hydraulic performance should be represented by 3D numerical models. The modeling tools can be investigated based on actual water head and discharge data.

CFD modeling technology is important in the future for testing the efficiency and performance of dams and turbines by reducing the cost of testing and the need for physical adjustment while simultaneously increasing the operational competence of the design. This modeling technology allows developers to design better prototypes and establish alterations to achieve higher-performing models, decreasing the need for onsite testing. CFD is able to significantly increase the turbine efficiency and the draft recovery factor using a vortex generator in the draft tube, while studies on draft tube flow pattern prediction are lacking [217-219]. More detailed studies using the CFD method should aim to improve the overall efficiency of blade contour tuning, to reduce tip leakage, refine the coarseness and friction in the surface area, and reduce water leakage and hammer effect.

The main dam-hydropower-related plant problems appear to be cavitation in the draft tube, hydraulic turbine structure design, and powerhouse vibration. Many researchers [182,187-189,220] 
have studied how to solve the cavitation problem in the draft tube, vibration effect in the powerhouse due to turbine operation, and how to maximize the power generation. Sufficient predictions for cavitation have been provided via numerical methods; however, the numerical results must be verified via detection methods.

CFD technology has been found to be effective for analyzing the cavitation zone and associated decreases in inefficiency. The validation of models with the prevailing outcomes allows researchers to redesign, select, and forecast performance [221]. Among the models applied by CFD, Rayleigh-Plesset is the leading model for modeling and prediction of many characteristics of cavitation including the formation, decay, and vapor production rate [222]. In the future, several other competent models could be introduced to achieve better reduction accuracy by applying methods like large eddy simulation (LES), direct numerical simulation (DNS), and partially averaged Navier-Stokes (PANS) [223-225]. Algorithms still need to be developed for CFD methods for analyzing cavitating flow simulation. In addition to better models and algorithms, experimental validation and data from actual problems during operation are required.

Various designs have been proposed to enhance the hydro-turbine efficiency, which have been tested via numerical simulations [146,163,168,177,178,195-197,201-203]. Vibration due to powerhouse operation has been analyzed by several researchers [151,176,201-203,205,206,208,209,226]; however, more comprehensive studies should be completed to connect the effect of vibration from turbines operation with design on the dam body, to assure dam safety.

Hydropower is a renewable, cost-effective, and flexible method to generate electricity and dam structures have been successfully exploited for profits during the production of green energy. However, the operation of these facilities is influenced by many events; engineers, researchers, and project managers need to consider this to successfully achieve their goal. Some of these factors include [227-230]:

(1) Maximum and minimum water output choices,

(2) Effect of vibration on the life of the operation,

(3) Electricity-related deviations,

(4) Environmental constraints,

(5) Revenue variation and its effect on operational activities,

(6) Market variation,

(7) Policy changes, and

(8) Hazards during operation affecting productivity.

Hydro-dam projects have considerable potentials in generating cost-effective and environment-friendly energy; however, the most cost-effective construction projects are located in hilly areas, which usually have low population density, leading to low revenue; thus, more researches on micro-hydro-systems are needed. These studies will help low-income and developing countries to promote the application of green hydro projects. To date, various projects around the world have been initiated (such as in Nepal, Sri Lanka, Peru, and Indonesia) with the same objective [88]. With increasing computation performance in this field and other improvements in civil, mechanical, electrical, and other engineering fields, increasingly improved and efficient design of dams can be achieved. Researchers should also consider the development of more efficient energy production methods, investment strategies, low head turbines, cheaper automatic operating systems, cost-effective and durable materials, modifications to turbines based on real situations, maintenance issues, as well as to ensure the least effect of the operation on the local environment.

The dam structures are constantly under geo-stress conditions, such as the displacement loss due to the elastic deformation of the surrounding rock. Thus, researchers should consider displacement loss during stability analysis to prevent accidents. Some conventional tests for this task are available, like the block-shear test, jacking test, the borehole jack, and the plate loading test, which are expensive and time-consuming $[231,232]$. Techniques, such as back analysis, are required that are easy to apply, 
cheaper, and have more efficient results [233]. Similarly, the application of empirical relationship techniques such as Hoek and Diederichs equations, have been proven to be more accurate [234]. However, few comparative studies of dam structure engineering have been published.

In addition to the various measures and uncertainties discussed in the literature to reduce the cost of analyses and projects, artificial intelligence (AI) application is still not fully realized in this field; numerical techniques are still more popular. However, the application of $\mathrm{AI}$ in a rock displacement study using Gaussian process and integrating it with an optimizer (i.e., particle swarm optimization) has shown good results [233]. Application of AI in small hydropower can save resources and optimize the efficacy of power generation [234]. For this task, the application of AI optimizers and other meta-heuristic algorithms could be beneficial.

The world's largest projects, like the Three Gorges Dam in the Yangtze River in China, has benefits as well as side effects. This dam construction is expensive, and the mitigation effort adds to the costs. For instance, for the Three Gorges Dam, the 10-year mitigation cost was estimated to be USD $\$ 26.45$ billion, since the dam has led to the deterioration of water quality, soil erosion, spreading of snail-borne disease, endangered fish and animals, affecting agricultural land, landslides, uprooting millions of people, and damaging the environment [235-237]. This kind of unfortunate outcome was expected by planners and engineers. Even though these projects have much to offer with respect to flood control and renewable power generation, these benefits come at a price. These limitations to hydro-dam construction can be mitigated by understanding dam properties, hydrological alteration, and hydro-biological diversity when applying advanced and regulated norms. For example, dams with rare fish should have regulated flow and a flood pulse component; for dams that alter the hydrological regime simulation and recovery should be completed; and for dams with potential environmental emergencies, cascade reservoir regulation should be implemented [238]. The construction site of the dam should be thoroughly investigated so that the environmental effects can be minimized, which can be achieved by spatial optimization of hydropower dam location via modeling [239].

The main application of hydro-dams is energy generation. Energy generation can be maximized using short-term weather forecasts. A model based on the various variables affecting the dam, such as short-term precipitation, wind speed, runoff, and streamflow from a global forecast system, could help to improve the operational efficiency, which would, in turn, increase the energy production. This technique does not affect the flood management or safety regulation of the dam. Along with this technique, an early warning system could be designed for flash floods, which can be predicted by hydrological modeling [240].

\section{Possible Future Research Directions}

Several other possible future studies should be considered:

(1) The operation of the powerhouse at the dam site is one of the important factors that should be considered in the analysis of dam safety. The effect of seismic activity on the dam body should be integrated with the powerhouse effect. Most of the published studies either only focused on reducing the impact of cavitation and pressure fluctuations in the turbine draft tube or on the analysis of seismic effect on the dam bodies. Hence, integration of the vibrational effect due to the operation of reaction turbines with and without seismic effects should be further investigated.

(2) Over time, various advancing techniques have been used to model dam operation. Among several techniques, AI models have achieved great results and shown promises in the near future. AI models use various optimization techniques and models, which help designers to comprehensively assess, predict, and manage large amounts of data. This, in turn, helps policymakers, engineers, and project managers to manage and operate the system more efficiently. Many AI models have been applied to the modeling and operation of dams and reservoirs considering different stochastic hydrological parameters [241]. Many AI models have been employed; however, faster problem-solving models are required along with better optimizers, 
including methods that can select the input and manage non-linear data and more experimental data to develop an effective model.

(3) Turbine productivity is usually determined based on the maximum and the minimum upstream water levels. Hence, for optimal turbine system operation, computations of the principal stresses within the dam body and powerhouse should be examined based on the water level.

(4) In the majority of the published studies, turbine model evaluations within the dam powerhouse were investigated individually. Conceptually, this is not practical from an engineering point of view. The vibrational effect on the dam body and the powerhouse should be simulated as a cohesive unit.

(5) Dam emergency action plans should be implemented, coupled with the development of improved systems for flood prediction.

(6) The reliability of the dam gates must be improved to ensure the availability of all dams during a flood.

(7) The main body of the dams should be grouted using cement to reduce leakages and improve performance.

(8) The foundation drains must be renovated to ensure the drainage system is working properly; a good dissipation of uplift pressures must also be ensured.

(9) Detailed seismic studies must be performed to analyze the chances of seismic-event-related failure modes.

(10) A risk model architecture must be implemented.

(11) Advancements in computer-based capabilities have resulted in the development of numerous methods for predicting the extent of cavitation development and its characteristics over propeller blades. Hence, CFD can be used to conduct turbine cavitation studies using a barotropic state equation.

(12) The availability of data is crucial for dam construction, hydropower generation, ecological and hydrological protection, and smooth operational activities. However, regular, continuous, and reliable data are difficult to obtain. A well-equipped and strategically designed network of hydrological, water quality, and biological monitoring stations should be in place to collect data on aquatic animals, flow regime, water temperature, nutrients, and sediment load [242]. The environmental impact basement should be more detailed [243]. These assessments could help with more consistent and reliable policymaking, thereby increasing the applications of hydro-electrical dams.

(13) By applying various assessments, monitoring, and simulation using previous dam data or prototype structure operational data, much better hydro-dams can be designed. In addition to that, for the more efficient performance of turbines and dams, there is need of economical maintenance methods, and mini-hydro plants are better suited for these purposes. They are cheaper, efficient and operation and maintenance is simpler than large projects. To increase the number of clean and sustainable energy sources, governments can support initiatives by providing financial subsidies like fixed feed-in or premium tariffs [244]. However, the number of subsidies provided and environmental impact per $1 \mathrm{MW}$ production of energy must be estimated.

Author Contributions: Conceptualization, Z.M.Y., H.A.A., N.A.-A., A.M.S.A.; Formal analysis, T.T., Z.M.Y., M.S.A., M.A., H.A.A., S.Z., A.M.S.A.-J., N.A.-A., H.T. and A.M.S.A.; Investigation, T.T., Z.M.Y., M.S.A., M.A., H.A.A., S.Z., A.M.S.A.-J., H.T. and A.M.S.A.; Project administration, Z.M.Y.; Supervision, Z.M.Y., H.A.A., N.A.-A. and A.M.S.A.; Visualization, T.T., Z.M.Y., M.S.A., M.A., H.A.A., S.Z., A.M.S.A.-J., H.T. and A.M.S.A.; Writing-original draft, T.T., Z.M.Y., M.S.A., M.A., H.A.A., S.Z., A.M.S.A.-J., N.A.-A., H.T. and A.M.S.A.; Writing-review \& editing, T.T., Z.M.Y., M.S.A., M.A., H.A.A., S.Z., A.M.S.A.-J., N.A.-A., H.T. and A.M.S.A. All authors have read and agreed to the published version of the manuscript.

Funding: This research received no external funding.

Conflicts of Interest: The authors declare no conflict of interest. 


\section{References}

1. Zhang, L.; Peng, M.; Chang, D.; Xu, Y. Dam Failure Mechanisms and Risk Assessment; John Wiley \& Sons: Hoboken, NJ, USA, 2015; ISBN 9781118558522.

2. Bosshard, P. China Dams the World. World Policy J. 2009, 26, 43-51. [CrossRef]

3. Nasir, B.A. Design considerations of micro-hydro-electric power plant. Energy Procedia 2014, 50, 19-29. [CrossRef]

4. Weinberg, A.M. 'Immortal'energy systems and intergenerational justice. Energy Policy 1985, 13, 51-59. [CrossRef]

5. Mahmood, K.; Mundial, B. Reservoir Sedimentation: Impact, Extent, and Mitigation; World Bank: Washington, DC, USA, 1987.

6. Kirchherr, J.; Charles, K.J. The social impacts of dams: A new framework for scholarly analysis. Environ. Impact Assess. Rev. 2016, 60, 99-114. [CrossRef]

7. Lerer, L.B.; Scudder, T. Health impacts of large dams. Environ. Impact Assess. Rev. 1999, 19, $113-123$. [CrossRef]

8. Lejeune, A.; Hui, S.L. Hydro Power: A Multi Benefit Solution for Renewable Energy. In Comprehensive Renewable Energy; Elsevier: Amsterdam, The Netherlands, 2012; Volume 6, pp. 15-47.

9. Padhy, M.K.; Saini, R.P. A review on silt erosion in hydro turbines. Renew. Sustain. Energy Rev. 2008, 12, 1974-1987. [CrossRef]

10. Kjølle, A. Hydropower in Norway: Mechanical Equipment. In Proceedings of the IAHR Congress, Beijing, China, 16-21 September 2001.

11. Neopane, H.P. Sediment Erosion in Hydro Turbines; Tapir Uttrykk: Trondheim, Norway, 2010.

12. Yang, Y.; Chen, J.; Xiao, M. Analysis of seismic damage of underground powerhouse structure of hydropower plants based on dynamic contact force method. Shock Vib. 2014, 2014. [CrossRef]

13. Dorji, U.; Ghomashchi, R. Hydro turbine failure mechanisms: An overview. Eng. Fail. Anal. 2014, 44, 136-147. [CrossRef]

14. Mejia, L.H.; Seed, H.B. Comparison of 2-D and 3-D dynamic analyses of earth dams. J. Geotech. Eng. 1983. [CrossRef]

15. Khosravi, S.; Heydari, M.M. Modelling of Concrete Gravity Dam Including Dam-Water-Foundation Rock Interaction. World Appl. Sci. J. 2013, 22, 538-546.

16. Sarkar, R.; Paul, D.K.; Stempniewski, L. Influence of reservoir and foundation on the nonlinear dynamic response of concrete gravity dams. ISET J. Earthq. Technol. 2007, 44, 377-389.

17. Zeidan, B.A. Effect of foundation flexibility on dam-reservoir-foundation interaction. In Proceedings of the Eighteenth International Water Technology Conference, Sharm El Sheikh, Egypt, 12-15 March 2015.

18. Ebrahimian, B. Non-Linear Numerical Analysis of Earthquake-Induced Deformation of Earth-Fill Dams; INTECH Open Access Publisher: Rijeka, Croatia, 2012; ISBN 9535100254.

19. Mircevska, V.J.; Bickovski, V.; Garevski, M. A 3D nonlinear dynamic analysis of a rock-fill dam based on IZIIS software. Acta Geotech. Slov. 2007, 4, 16-32.

20. Bosioc, A.I.; Tanasa, C.; Muntean, S.; Susan-Resiga, R.F. Unsteady pressure measurements and numerical investigation of the jet control method in a conical diffuser with swirling flow. In Proceedings of the IOP Conference Series: Earth and Environmental Science; IOP Publishing: Bristol, UK, 2010; Volume 12, p. 12017.

21. Casanova García, F.; Mantilla Viveros, C.A. Experimental analysis of the vibration on the draft tube of a Francis hydraulic turbine during operation at different power levels. Rev. Fac. Ing. Univ. Antioquia 2010, 55, 90-98.

22. Lai, X.D.; Liao, G.L.; Zhu, Y.; Zhang, X.; Gou, Q.Q.; Zhang, W.B. Lateral vibration of hydro turbine-generator rotor with varying stiffness of guide bearings. In Proceedings of the IOP Conference Series: Earth and Environmental Science; IOP Publishing: Bristol, UK, 2012; Volume 15, p. 42006.

23. Akkermann, J.; Runte, T.; Krebs, D. Ship lift at Three Gorges Dam, China-design of steel structures. Steel Constr. 2009, 2, 61-71. [CrossRef]

24. Narita, K. Design and Construction of Embankment Dams. 2000. Available online: http://aitech.ac.jp/ $\sim\{\}$ narita/tembankmentdam1.pdf (accessed on 21 February 2020).

25. Doyle, M.W.; Harbor, J.M.; Stanley, E.H. Toward policies and decision-making for dam removal. Environ. Manage. 2003, 31, 453-465. [CrossRef] 
26. Luo, Y.; Chen, L.; Xu, M.; Tong, X. Review of dam-break research of earth-rock dam combining with dam safety management. Procedia Eng. 2012, 28, 382-388.

27. Altarejos-García, L.; Escuder-Bueno, I.; Serrano-Lombillo, A.; de Membrillera-Ortuño, M.G. Methodology for estimating the probability of failure by sliding in concrete gravity dams in the context of risk analysis. Struct. Saf. 2012, 36, 1-3. [CrossRef]

28. Foster, M.; Fell, R.; Spannagle, M. The statistics of embankment dam failures and accidents. Can. Geotech. J. 2000, 37, 1000-1024. [CrossRef]

29. Mishra, A.K. Engineering Geology, 1st ed.; S.CHAND \&COMPANY PVT. LTD: New Delhi, India, 2014; ISBN 81-219-4322-1.

30. Raleigh. Dam Operation, Maintenance and Inspection Manual; North Carolina Department of Environment and Natural Resources Division of Land Resources Land Quality Section: Raleigh, NC, USA, 1989.

31. Chen, S.-H. Hydraulic Structures; Springer: Berlin/Heidelberg, Germany, 2015; ISBN 978-3-662-47330-6.

32. Ali, A.A.; Al-Ansari, N.A.; Knutsson, S. Morphology of Tigris River within Baghdad City. Hydrol. Earth Syst. Sci. 2012, 16, 3783. [CrossRef]

33. Hariri-Ardebili, M.A.; Seyed-Kolbadi, S.M. Seismic cracking and instability of concrete dams: Smeared crack approach. Eng. Fail. Anal. 2015, 52, 45-60. [CrossRef]

34. Ratnayaka, D.D.; Brandt, M.J.; Johnson, M. Water Supply; Butterworth-Heinemann: Oxford, UK, 2009; ISBN 0080940846.

35. Ghaemmaghami, A.R.; Ghaemian, M. Experimental seismic investigation of Sefid-rud concrete buttress dam model on shaking table. Earthq. Eng. Struct. Dyn. 2008, 37, 809-823. [CrossRef]

36. Wieland, M. Features of seismic hazard in large dam projects and strong motion monitoring of large dams. Front. Archit. Civ. Eng. China 2010, 4, 56-64. [CrossRef]

37. Akbari, J.; Ahmadi, M.T.; Moharrami, H. Advances in concrete arch dams shape optimization. Appl. Math. Model. 2011, 35, 3316-3333. [CrossRef]

38. Wang, R.K.; Chen, L.; Zhang, C. Seismic design of Xiluodu ultra-high arch dam. Water Sci. Eng. 2018, 11, 288-301. [CrossRef]

39. Zarfl, C.; Lumsdon, A.E.; Berlekamp, J.; Tydecks, L.; Tockner, K. A global boom in hydropower dam construction. Aquat. Sci. 2014, 77, 161-170. [CrossRef]

40. Horlacher, H.; Heyer, T.; Ramos, C.M.; Da Silva, M.C. Management of Hydropower Impacts through Construction and Operation; Elsevier: Amsterdam, The Netherlands, 2012.

41. POFF, N.L.; HART, D.D. How Dams Vary and Why It Matters for the Emerging Science of Dam Removal. Bioscience 2002, 52, 659. [CrossRef]

42. IIED. Dams and Development: A New Framework for Decision-Making: Overview of the Report by the World Commission on Dam; Issue Paper 108, Drylands Programme; Earthscan: London, UK, 2001.

43. Wehrmann, H.; Hübl, J.; Holzinger, G. Classification of Dams in Torrential Watersheds. In Proceedings of the INTERPRAEVENT International Symposium Disaster Mitigation of Debris Flows, Slope Failures and Landslides, Niigata, Japan, 25-29 September 2006; pp. 829-838.

44. Goldin, A.L.; Rasskazov, L.N.; Zeidler, R.B. Design of earth dams; Routledge: London, UK, 2017; ISBN 9781351455848.

45. Bretas, E.M.; Lemos, J.V.; Lourenço, P.B. Hydromechanical analysis of masonry gravity dams and their foundations. Rock Mech. rock Eng. 2013, 46, 327-339. [CrossRef]

46. Qu, Y.; Zou, D.; Kong, X.; Liu, J.; Zhang, Y.; Yu, X. Seismic damage performance of the steel fiber reinforced face slab in the concrete-faced rockfill dam. Soil Dyn. Earthq. Eng. 2019, 119, 320-330. [CrossRef]

47. Sherard, J.L.; Cooke, J.B. Concrete-face rockfill dam: I. Assessment. J. Geotech. Eng. 1987, 113, 1096-1112. [CrossRef]

48. Rane, A.V.; Thakur, S.; Thakur, R. Rubber Dam-An Introduction. In Hydraulic Rubber Dam; Elsevier: Amsterdam, Netherlands, 2019; pp. 1-9.

49. Previati, M.; Canone, D.; Bevilacqua, I.; Boetto, G.; Pognant, D.; Ferraris, S. Evaluation of wood degradation for timber check dams using time domain reflectometry water content measurements. Ecol. Eng. 2012, 44, 259-268. [CrossRef]

50. Seed, H.B. Considerations in the earthquake-resistant design of earth and rockfill dams. Geotechnique 1979, 29, 215-263. [CrossRef] 
51. Severn, R.T.; Jeary, A.P.; Ellis, B.R. BRE FORCED VIBRATION TESTS AND THEORETICAL STUDIES ON DAMS. Proc. Inst. Civ. Eng. 1980, 69, 605-634.

52. Brownjohn, J.M.W.; Severn, R.T.; Taylor, C.A. Ambient Vibration Survey of Contra Dam; University of Bristol, Department of Civil Engineering: Bristol, UK, 1986.

53. Andrianopoulos, K.I.; Papadimitriou, A.G.; Bouckovalas, G.D.; Karamitros, D.K. Insight into the seismic response of earth dams with an emphasis on seismic coefficient estimation. Comput. Geotech. 2014, 55, 195-210. [CrossRef]

54. Dakoulas, P.; Gazetas, G. Seismic shear vibration of embankment dams in semi-cylindrical valleys. Earthq. Eng. Struct. Dyn. 1986, 14, 19-40. [CrossRef]

55. Gazetas, G.; Dakoulas, P. Seismic analysis and design of rockfill dams: state-of-the-art. Soil Dyn. Earthq. Eng. 1992, 11, 27-61. [CrossRef]

56. Kontoe, S.; Han, B.; Pelecanos, L.; Zdravkovic, L. Seismic response of earthfill and rockfill embankment dams. In Proceedings of the 3rd Meeting of EWG Dams and Earthquakes—an International Symposium, Lisbon, Portugal, 6-8 May 2019.

57. Chakraborty, S.; Das, J.T.; Puppala, A.J.; Banerjee, A. Natural frequency of earthen dams at different induced strain levels. Eng. Geol. 2019, 248, 330-345. [CrossRef]

58. Esmaielzadeh, S.; Ahmadi, H.; Hosseini, S.A. Damage detection in concrete gravity dams using signal processing algorithms based on earthquake vibrations. J. Vibroeng. 2019, 21, 2196-2215.

59. Esmaielzadeh, S.; Ahmadi, H.; Hosseini, S.A. Damage Detection of Concrete Gravity Dams using Hilbert-Huang Method. J. Appl. Eng. Sci. 2019, 8, 7-16. [CrossRef]

60. Bukenya, P.; Moyo, P.; Beushausen, H.; Oosthuizen, C. Health monitoring of concrete dams: A literature review. J. Civ. Struct. Heal. Monit. 2014, 4, 235-244. [CrossRef]

61. Chang, N.-Y.; Oncul, F. A Parametric Study on Seismic Behavior of a Composite Dam. In Proceedings of the Soil Dynamics and Liquefaction 2000; American Society of Civil Engineers: Reston, VA, USA, 2000; pp. 178-190.

62. Kim, D.-S.; Kim, M.-K.; Kim, S.-H.; Choo, Y.-W. Seismic behaviors of earth-core, concrete-faced-rock-fill, and composite dams. Citeseer 2012.

63. Cui, J.; Shen, Z. Characteristics of Earthquake Induced Permanent Deformation of a High Composite Dam with Asphalt Concrete Core Wall. Water Resour. Power 2010, 28, 73-77.

64. Sevim, B.; Bayraktar, A.; Altunişik, A.C. Finite element model calibration of berke arch dam using operational modal testing. J. Vib. Control 2011, 17, 1065-1079. [CrossRef]

65. Schleiss, A.J.; Boes, R.M. Dams and Reservoirs under Changing Challenges; CRC press: Boca Raton, FL, USA, 2011; ISBN 0203804090.

66. Zhang, S.; Wang, G.; Yu, X. Seismic cracking analysis of concrete gravity dams with initial cracks using the extended finite element method. Eng. Struct. 2013, 56, 528-543. [CrossRef]

67. Amini, F.; Sama, K.M. Behavior of stratified sand-silt-gravel composites under seismic liquefaction conditions. Soil Dyn. Earthq. Eng. 1999, 18, 445-455. [CrossRef]

68. Sharma, A.K.; Thakur, N.S. Energy situation, current status and resource potential of run of the river (RoR) large hydro power projects in Jammu and Kashmir: India. Renew. Sustain. Energy Rev. 2017, 78, $233-251$. [CrossRef]

69. Li, J.; Ameen, A.; Mohammad, T.; Al-Ansari, N.; Yaseen, Z. A Systematic Operation Program of a Hydropower Plant Based on Minimizing the Principal Stress: Haditha Dam Case Study. Water 2018, 10, 1270. [CrossRef]

70. Ameen, A.; Ibrahim, Z.; Othman, F.; Al-Ansari, N.; Yaseen, Z. Minimizing the principle stresses of powerhoused Rock-Fill dams using control turbine running units: Application of Finite Element Method. Water 2018, 10, 1138. [CrossRef]

71. Avakyan, T. Distribution Systems with Renewable Sources. Master's Thesis, Czech Technical University, Prague, Czech Republic, 2017.

72. Gielen, D. Renewable energy technologies: cost analysis series. Sol Photovolt 2012, 1, 52.

73. Quaranta, E.; Revelli, R. Gravity water wheels as a micro hydropower energy source: A review based on historic data, design methods, efficiencies and modern optimizations. Renew. Sustain. Energy Rev. 2018, 97, 414-427. [CrossRef]

74. Emiliano Corà, (EUREC). Hydropower Technologies: The State-of-the-Art. 2019. Available online: https://consultation.hydropower-europe.eu/assets/consultations/2019.08.13\%20HydropowerTechnology_ State\%20of\%20the\%20Art\%20FINAL.pdf (accessed on 21 February 2020). 
75. Wahlstrom, E.E. Dams, Dam Foundations, and Reservoir Sites. Developments in Geotechnical Engineering volume 6; Elsevier Scientific Publishing Company: Amsterdam, The Netherlands; Oxford, UK; New York, NY, USA, 1975; Volume 6.

76. Suul, J.A.; Uhlen, K.; Undeland, T. Variable speed pumped storage hydropower for integration of wind energy in isolated grids: case description and control strategies. In Proceedings of the Nordic Workshop on Power and Industrial Electronics (NORPIE/2008), Espoo, Finland, 9-11 June 2008; Helsinki University of Technology: Espoo, Finland, 2008.

77. Razan, J.I.; Islam, R.S.; Hasan, R.; Hasan, S.; Islam, F. A comprehensive study of micro-hydropower plant and its potential in Bangladesh. ISRN Renew. Energy 2012, 2012. [CrossRef]

78. Sharma, H.; Singh, J. Run off river plant: status and prospects. Int. J. Innov. Technol. Explor. Eng. 2013, 3, 210-213.

79. Sangal, S.; Garg, A.; Kumar, D. Review of optimal selection of turbines for hydroelectric projects. Int. J. Emerg. Technol. Adv. Eng. 2013, 3, 424-430.

80. Cobb, B.R.; Sharp, K. V Impulse (Turgo and Pelton) turbine performance characteristics and their impact on pico-hydro installations. Renew. Energy 2013, 50, 959-964. [CrossRef]

81. Linhardt, H.D.; Silvern, D.H. Analysis of partial admission axial impulse turbines. ARS J. 1961, 31, $297-308$. [CrossRef]

82. Židonis, A.; Benzon, D.S.; Aggidis, G.A. Development of hydro impulse turbines and new opportunities. Renew. Sustain. Energy Rev. 2015, 51, 1624-1635. [CrossRef]

83. Jayashankar, V.; Anand, S.; Geetha, T.; Santhakumar, S.; Kumar, V.J.; Ravindran, M.; Setoguchi, T.; Takao, M.; Toyota, K.; Nagata, S. A twin unidirectional impulse turbine topology for OWC based wave energy plants. Renew. Energy 2009, 34, 692-698. [CrossRef]

84. Setoguchi, T.; Santhakumar, S.; Maeda, H.; Takao, M.; Kaneko, K. A review of impulse turbines for wave energy conversion. Renew. Energy 2001, 23, 261-292. [CrossRef]

85. Quaranta, E. Optimal Rotational Speed of Kaplan and Francis Turbines with Focus on Low-Head Hydropower Applications and Dataset Collection. J. Hydraul. Eng. 2019, 145, 4019043. [CrossRef]

86. Židonis, A.; Aggidis, G.A. State of the art in numerical modelling of Pelton turbines. Renew. Sustain. Energy Rev. 2015, 45, 135-144. [CrossRef]

87. Trivedi, C.; Gandhi, B.; Michel, C.J. Effect of transients on Francis turbine runner life: a review. J. Hydraul. Res. 2013, 51, 121-132. [CrossRef]

88. Paish, O. Small hydro power: Technology and current status. Renew. Sustain. Energy Rev. 2002, 6, 537-556. [CrossRef]

89. Negru, R.; Muntean, S.; Marsavina, L.; Susan-Resiga, R.; Pasca, N. Computation of stress distribution in a Francis turbine runner induced by fluid flow. Comput. Mater. Sci. 2012, 64, 253-259. [CrossRef]

90. Urquiza, G.; Garcia, J.C.; Gonzalez, J.G.; Castro, L.; Rodriguez, J.A.; Basurto-Pensado, M.A.; Mendoza, O.F. Failure analysis of a hydraulic Kaplan turbine shaft. Eng. Fail. Anal. 2014, 41, 108-117. [CrossRef]

91. Moradi, S.; Yeganeh, A.; Salimi, M. CFD-modeling of effects of draft tubes on operating condition in spouted beds. Appl. Math. Model. 2013, 37, 1851-1859. [CrossRef]

92. Ribeiro, A.F.; Guedes, M.C.M.; Smirnov, G.V.; Vilela, S. On the optimal control of a cascade of hydro-electric power stations. Electr. Power Syst. Res. 2012, 88, 121-129. [CrossRef]

93. Kougias, I.; Aggidis, G.; Avellan, F.; Deniz, S.; Lundin, U.; Moro, A.; Muntean, S.; Novara, D.; Pérez-Díaz, J.I.; Quaranta, E. Analysis of emerging technologies in the hydropower sector. Renew. Sustain. Energy Rev. 2019, 113, 109257. [CrossRef]

94. Muhirwa, A.; Cai, W.-H.; Su, W.-T.; Liu, Q.; Binama, M.; Li, B.; Wu, J. A Review on Remedial Attempts to Counteract the Power Generation Compromise from Draft Tubes of Hydropower plants. Renew. Energy 2019. [CrossRef]

95. De Araújo, J.; Awruch, A.M. Probabilistic finite element analysis of concrete gravity dams. Adv. Eng. Softw. 1998, 29, 97-104. [CrossRef]

96. Versteeg, H.K.; Malalasekera, W.; Orsi, G.; Ferziger, J.H.; Date, A.W.; Anderson, J.D. An Introduction to Computational Fluid Dynamics—The Finite Volume Method; Pearson Education Limited: London, UK, 1995; ISBN 9783540594345.

97. Bhajantri, M.R.; Eldho, T.I.; Deolalikar, P.B. Hydrodynamic modelling of flow over a spillway using a two-dimensional finite volume-based numerical model. Sadhana 2006, 31, 743-754. [CrossRef] 
98. Cervera, M.; Oliver, J.; Faria, R. Seismic evaluation of concrete dams via continuum damage models. Earthq. Eng. Struct. Dyn. 1995, 24, 1225-1245. [CrossRef]

99. Callari, C.; Abati, A. Finite element methods for unsaturated porous solids and their application to dam engineering problems. Comput. Struct. 2009, 87, 485-501. [CrossRef]

100. Eastwood, J.W. An introduction to computational fluid mechanics. Comput. Phys. Commun. 1980, 20, 321-322. [CrossRef]

101. Valiani, A.; Caleffi, V.; Zanni, A. Case study: Malpasset dam-break simulation using a two-dimensional finite volume method. J. Hydraul. Eng. 2002, 128, 460-472. [CrossRef]

102. Vosoughifar, H.R.; Dolatshah, A.; Sadat Shokouhi, S.K. Discretization of multidimensional mathematical equations of dam break phenomena using a novel approach of finite volume method. J. Appl. Math. 2013, 2013. [CrossRef]

103. Ferziger, J.H.; Peric, M. Computational Methods for Fluid Dynamics; Springer Science \& Business Media: Berlin/Heidelberg, Germany, 2012; ISBN 3642560261.

104. Khan, L.A.; Wicklein, E.A.; Rashid, M.; Ebner, L.L.; Richards, N.A. Computational fluid dynamics modeling of turbine intake hydraulics at a hydropower plant. J. Hydraul. Res. 2004, 42, 61-69. [CrossRef]

105. Teklemariam, E.; Korbaylo, B.W.; Groeneveld, J.L.; Fuchs, D.M. Computational fluid dynamics: Diverse applications in hydropower project's design and analysis. In Proceedings of the CWRA 55th Annual Conference, Winnipeg, MB, Canada, 11-14 June 2002.

106. Pascau, A.; Pérez, C.; Serón, F.J. A comparison of segregated and coupled methods for the solution of the incompressible Navier-Stokes equations. Commun. Numer. Methods Eng. 1996, 12, 617-630. [CrossRef]

107. Benzon, D.S.; Aggidis, G.A.; Anagnostopoulos, J.S. Development of the Turgo Impulse turbine: Past and present. Appl. Energy 2016, 166, 1-18. [CrossRef]

108. Quaranta, E.; Katopodis, C.; Revelli, R.; Comoglio, C. Turbulent flow field comparison and related suitability for fish passage of a standard and a simplified low-gradient vertical slot fishway. River Res. Appl. 2017, 33, 1295-1305. [CrossRef]

109. Yilmazturk, S.M.; Arici, Y.; Binici, B. Seismic assessment of a monolithic RCC gravity dam including three dimensional dam-foundation-reservoir interaction. Eng. Struct. 2015, 100, 137-148. [CrossRef]

110. Xiong, M.; Huang, Y. Stochastic seismic response and dynamic reliability analysis of slopes: A review. Soil Dyn. Earthq. Eng. 2017, 100, 458-464. [CrossRef]

111. Fenves, G.; Chopra, A.K. Simplified earthquake analysis of concrete gravity dams: Separate hydrodynamic and foundation interaction effects. J. Eng. Mech. 1985, 111, 715-735. [CrossRef]

112. Bouaanani, N.; Paultre, P.; Proulx, J. A closed-form formulation for earthquake-induced hydrodynamic pressure on gravity dams. J. Sound Vib. 2003, 261, 573-582. [CrossRef]

113. Bouaanani, N.; Paultre, P. A new boundary condition for energy radiation in covered reservoirs using BEM. Eng. Anal. Bound. Elem. 2005, 29, 903-911. [CrossRef]

114. Birk, C.; Ruge, P. Representation of radiation damping in a dam-reservoir interaction analysis based on a rational stiffness approximation. Comput. Struct. 2007, 85, 1152-1163. [CrossRef]

115. Bouaanani, N.; Lu, F.Y. Assessment of potential-based fluid finite elements for seismic analysis of dam-reservoir systems. Comput. Struct. 2009, 87, 206-224. [CrossRef]

116. Fathi, A.; Lotfi, V. EFFECTS OF RESERVOIR LENGTH ON DYNAMIC ANALYSIS OF CONCRETE GRAVITY DAMS. In Proceedings of the 14th World Conference on Earthquake Engineering, Beijing, China, 12-17 October 2008.

117. Lotfi, V. Seismic analysis of concrete gravity dams by decoupled modal approach in time domain. Electron. J. Struct. Eng. 2003, 3, 102-116.

118. Shariatmadar, H. Modal Response of Dam-Reservoir-Foundation Interaction. J. Math. 2009.

119. Gui, M.-W.; Chiu, H.-T. Seismic response of Renyitan earth-fill dam. J. Geoengin. 2009, 4, 41-50.

120. Khazaee, A.; Lotfi, V. Application of perfectly matched layers in the transient analysis of dam-reservoir systems. Soil Dyn. Earthq. Eng. 2014, 60, 51-68. [CrossRef]

121. Lotfi, V. MAP-76: A Program for Analysis of Concrete Dams; Amirkabir University of Technology: Tehran, Iran, 2001.

122. Wang, X.; Jin, F.; Prempramote, S.; Song, C. Time-Domain Analysis of Gravity Dam-Reservoir Interaction Using High-Order Doubly Asymptotic Open Boundary. Seism. Saf. Eval. Concr. Dams 2013, 89, 139-171.

123. Miquel, B.; Bouaanani, N. Accounting for earthquake-induced dam-reservoir interaction using modified accelerograms. J. Struct. Eng. 2013, 139, 1608-1617. [CrossRef] 
124. Mehdipour, B. Effect of Foundation on Seismic Behavior of Concrete Dam Considering the Interaction of Dam-Reservoir. J. Basic Appl. Sci. Res. 2013, 3, 13-20.

125. Anastasiadis, A.; Klimis, N.; Makra, K.; Margaris, B. On seismic behaviour of a $130 \mathrm{~m}$ high rockfill dam: An integrated approach. In Proceedings of the 13th Conference on Earthquake Engineering, Vancouver, BC, Canada, 1-6 August 2004; p. 2933.

126. Ohmachi, T.; Tahara, T. Analyses on earthquake-induced settlement of the Aratozawa dam due to the 2008 Iwate-Miyagi Nairiku earthquake, Japan. In Proceedings of the Validation of Dynamic Analyses of Dams and Their Equipment: Edited Contributions to the International Symposium on the Qualification of Dynamic Analyses of Dams and their Equipments, Saint-Malo, France, 31 August-2 September 2016; CRC Press: Boca Raton, FL, USA, 2018; p. 277.

127. Mouyeaux, A.; Carvajal, C.; Bressolette, P.; Peyras, L.; Breul, P.; Bacconnet, C. Probabilistic stability analysis of an earth dam by Stochastic Finite Element Method based on field data. Comput. Geotech. 2018, 101, $34-47$. [CrossRef]

128. Løkke, A.; Chopra, A.K. Direct finite element method for nonlinear earthquake analysis of concrete dams: Simplification, modeling, and practical application. Earthq. Eng. Struct. Dyn. 2019, 48, 818-842. [CrossRef]

129. Mohammadnezhad, H.; Ghaemian, M.; Noorzad, A. Seismic analysis of dam-foundation-reservoir system including the effects of foundation mass and radiation damping. Earthq. Eng. Eng. Vib. 2019, 18, 203-218. [CrossRef]

130. Ghaemian, M.; Noorzad, A.; Mohammadnezhad, H. Assessment of foundation mass and earthquake input mechanism effect on dam-reservoir-foundation system response. Int. J. Civ. Eng. 2019, 17, 473-480. [CrossRef]

131. Mouyeaux, A.; Carvajal, C.; Bressolette, P.; Peyras, L.; Breul, P.; Bacconnet, C. Probabilistic analysis of pore water pressures of an earth dam using a random finite element approach based on field data. Eng. Geol. 2019, 259, 105190. [CrossRef]

132. Sotoudeh, M.A.; Ghaemian, M.; Sarvghad Moghadam, A. Determination of limit-states for near-fault seismic fragility assessment of concrete gravity dams. Sci. Iran. 2019, 26, 1135-1155. [CrossRef]

133. Dakoulas, P. Longitudinal vibrations of tall concrete faced rockfill dams in narrow canyons. Soil Dyn. Earthq. Eng. 2012, 41, 44-58. [CrossRef]

134. Hariri-Ardebili, M.A.; Mirzabozorg, H. Reservoir fluctuation effects on seismic response of high concrete arch dams considering material nonlinearity. J. Civ. Eng. Res. 2011, 1, 9-20. [CrossRef]

135. Watanabe, H.; Kikuchi, K.; Cao, Z. Vibration Modes of a Rockfill Dam Based on the Observations of Microtremors and an Earthquake. Thammasat Int. J. Sci. Technol. 1996, 1.

136. Jafari, M.K.; Davoodi, M. Dynamic characteristics evaluation of Masjed-soleiman embankment dam using forced vibration test. In Proceedings of the 13th World Conference on Earthquake Engineering, Vancouver, BC, Canada, 1-6 August 2004.

137. Mirzabozorg, H.; Kordzadeh, A.; Hariri-Ardebili, M.A. Seismic response of concrete arch dams including dam-reservoir-foundation interaction using infinite elements. Electron. J. Struct. Eng. 2012, 12.

138. Albano, M.; Modoni, G.; Croce, P.; Russo, G. Assessment of the seismic performance of a bituminous faced rockfill dam. Soil Dyn. Earthq. Eng. 2015, 75, 183-198. [CrossRef]

139. Zhao, S.; Fan, S.; Chen, J. Quantitative assessment of the concrete gravity dam damage under earthquake excitation using electro-mechanical impedance measurements. Eng. Struct. 2019, 191, 162-178. [CrossRef]

140. Oliveira, S.; Alegre, A. Seismic and Structural Health Monitoring of Dams in Portugal. In Seismic Structural Health Monitoring; Springer: Berlin/Heidelberg, Germany, 2019; pp. 87-113.

141. Mirzabozorg, H.; Ghaemian, M.; Roohezamin, A. The reason of cracking in bottom gallery of SefidRud Buttress Dam and earthquake and post earthquake performance. Struct. Monit. Maint. 2019, 6, 103-124.

142. Ramancha, M.K.; Madarshahian, R.; Astroza, R.; Conte, J.P. Non-unique Estimates in Material Parameter Identification of Nonlinear FE Models Governed by Multiaxial Material Models Using Unscented Kalman Filtering. In Model Validation and Uncertainty Quantification, Volume 3; Springer: Berlin/Heidelberg, Germany, 2020; pp. 257-265.

143. Pennacchi, P.; Borghesani, P.; Chatterton, S. A cyclostationary multi-domain analysis of fluid instability in Kaplan turbines. Mech. Syst. Signal Process. 2015, 60, 375-390. [CrossRef]

144. Dixon, S.L.; Hall, C. Fluid Mechanics and Thermodynamics of Turbomachinery; Butterworth-Heinemann: Oxford, UK, 2013; ISBN 0123914108. 
145. Grassmann, H.; Ganis, M.L. On partially static Kaplan turbines. Renew. Energy 2005, 30, 179-186. [CrossRef]

146. Kumar, P.; Saini, R.P. Study of cavitation in hydro turbines-A review. Renew. Sustain. Energy Rev. 2010, 14, 374-383. [CrossRef]

147. Fu, T.; Deng, Z.D.; Duncan, J.P.; Zhou, D.; Carlson, T.J.; Johnson, G.E.; Hou, H. Assessing hydraulic conditions through Francis turbines using an autonomous sensor device. Renew. Energy 2016, 99, 1244-1252. [CrossRef]

148. Glatzel, T.; Litterst, C.; Cupelli, C.; Lindemann, T.; Moosmann, C.; Niekrawietz, R. Computational fluid dynamics (CFD) software tools for microfluidic applications-A case study. Comput. Fluids 2008, 37, 218-235. [CrossRef]

149. Lomax, H.; Pulliam, T.H.; Zingg, D.W. Fundamentals of computational fluid dynamics. Appl. Mech. Rev. 1999, 55, B61. [CrossRef]

150. Wang High-order computational fluid dynamics tools for aircraft design. Phil. Trans. R. Soc. A 2014, 372, 20130318. [CrossRef]

151. Zhang, L.; Wu, Q.; Ma, Z.; Wang, X. Transient vibration analysis of unit-plant structure for hydropower station in sudden load increasing process. Mech. Syst. Signal Process. 2019, 120, 486-504. [CrossRef]

152. Li, J.; Chen, D.; Liu, G.; Gao, X.; Miao, K.; Li, Y.; Xu, B. Analysis of the gyroscopic effect on the hydro-turbine generator unit. Mech. Syst. Signal Process. 2019, 132, 138-152. [CrossRef]

153. Paturu, P.; Vinoth Kanna, I.; Mallela, G. A detailed analysis of free vibration on $70 \mathrm{MW}$ hydro power turbine rotor. Int. J. Ambient Energy 2019, 1-8. [CrossRef]

154. Thapa, B.S.; Thapa, B.; Dahlhaug, O.G. Empirical modelling of sediment erosion in Francis turbines. Energy 2012, 41, 386-391. [CrossRef]

155. Iliescu, M.S.; Ciocan, G.D.; Avellan, F. Analysis of the Cavitating Draft Tube Vortex in a Francis Turbine Using Particle Image Velocimetry Measurements in Two-Phase Flow. J. Fluids Eng. 2008, 130, 021105. [CrossRef]

156. Stein, P.; Sick, M.; Dörfler, P.; White, P.; Braune, A. Numerical Simulation of the Cavitating Draft Tube Vortex in a Francis Turbine. In Proceedings of the 23rd IAHR Symposium on Hydraulic Machinery and Systems, Yokohama, Japan, 17-21 October 2006; Volume 228, p. 4711.

157. Jošt, D.; Lipej, A. Numerical prediction of non-cavitating and cavitating vortex rope in a Francis turbine draft tube. Strojniški vestnik-Journal Mech. Eng. 2011, 57, 445-456. [CrossRef]

158. QIAN, Z.D.; YANG, J.D.; HUAI, W.X. Numerical simulation and analysis of pressure pulsation in francis hydraulic turbine with air admission. J. Hydrodyn. 2007, 19, 467-472. [CrossRef]

159. Anup, K.C.; Thapa, B.; Lee, Y.-H. Transient numerical analysis of rotor-stator interaction in a Francis turbine. Renew. Energy 2014, 65, 227-235.

160. Luna-Ramírez, A.; Campos-Amezcua, A.; Dorantes-Gómez, O.; Mazur-Czerwiec, Z.; Muñoz-Quezada, R. Failure analysis of runner blades in a Francis hydraulic turbine-Case study. Eng. Fail. Anal. 2016, 59, 314-325. [CrossRef]

161. Gebreslassie, M.G.; Tabor, G.R.; Belmont, M.R. Numerical simulation of a new type of cross flow tidal turbine using OpenFOAM-Part I: Calibration of energy extraction. Renew. Energy 2013, 50, 994-1004. [CrossRef]

162. Minakov, A.V.; Platonov, D.V.; Dekterev, A.A.; Sentyabov, A.V.; Zakharov, A.V. The numerical simulation of low frequency pressure pulsations in the high-head Francis turbine. Comput. Fluids 2015, 111, 197-205. [CrossRef]

163. Trivedi, C.; Cervantes, M.J.; Gandhi, B.K.; Dahlhaug, O.G. Experimental and Numerical Studies for a High Head Francis Turbine at Several Operating Points. J. Fluids Eng. 2013, 135, 111102. [CrossRef]

164. Platonov, D.V.; Maslennikova, A.V.; Dekterev, D.A.; Minakov, A.V.; Abramov, A.V. Experimental study of pressure pulsations in the flow duct of a medium-size model hydroelectric generator with Francis turbine. Thermophys. Aeromechanics 2018, 25, 21-30. [CrossRef]

165. Luo, X.; Yu, A.; Yu, W.; Wang, L.; Xu, H. Pressure oscillation suppression by air admission in a Francis turbine draft tube. In Proceedings of the IOP Conference Series: Earth and Environmental Science; IOP Publishing: Bristol, UK, 2019; Volume 240, p. 22008.

166. Sakamoto, M.; Müller, A.; Andolfatto, L.; Hashii, T.; Yamaishi, K.; Avellan, F. Experimental investigation and numerical simulation of flow in the draft tube elbow of a Francis turbine over its entire operating range. In Proceedings of the IOP Conference Series: Earth and Environmental Science; IOP Publishing: Bristol, UK, 2019; Volume 240, p. 72009. 
167. Trivedi, C.; Agnalt, E.; Dahlhaug, O.G.; Brandastro, B.A. Signature analysis of characteristic frequencies in a Francis turbine. In Proceedings of the IOP Conference Series: Earth and Environmental Science; IOP Publishing: Bristol, UK, 2019; Volume 240, p. 72008.

168. Yu, A.; Zhou, D.; Chen, H. Numerical investigation of the behaviour of the cavitation rope in a Francis turbine with an optimized runner cone. In Proceedings of the IOP Conference Series: Earth and Environmental Science; IOP Publishing: Bristol, UK, 2019.

169. Pasche, S.; Gallaire, F.; Avellan, F. Origin of the synchronous pressure fluctuations in the draft tube of Francis turbines operating at part load conditions. J. Fluids Struct. 2019, 86, 13-33. [CrossRef]

170. Trivedi, C.; Dahlhaug, O.G. Interaction between trailing edge wake and vortex rings in a Francis turbine at runaway condition: Compressible large eddy simulation. Phys. Fluids 2018, 30, 075101. [CrossRef]

171. Cheng, H.; Zhou, L.J.; Zhao, Y.Z. Very large eddy simulation of the vortex rope in the draft tube of Francis turbine. In IOP Conference Series: Earth and Environmental Science; IOP Publishing: Bristol, UK, 2019; Volume 240, p. 022001.

172. Ko, P.; Kurosawa, S. Numerical simulation of turbulence flow in a Kaplan turbine Evaluation on turbine performance prediction accuracy. In IOP Conference Series: Earth and Environmental Science; IOP Publishing: Bristol, UK, 2014; Volume 22, p. 022006.

173. Javadi, A.; Nilsson, H. Unsteady numerical simulation of the flow in the U9 Kaplan turbine model. In IOP Conference Series: Earth and Environmental Science; IOP Publishing: Bristol, UK, 2014; Volume 22, p. 022001.

174. Favrel, A.; Müller, A.; Landry, C.; Yamamoto, K.; Avellan, F. Study of the vortex-induced pressure excitation source in a Francis turbine draft tube by particle image velocimetry. Exp. Fluids 2015, 56, 215. [CrossRef]

175. Mo, Z.; Xiao, J.; Wang, G. Numerical Research on Flow Characteristics around a Hydraulic Turbine Runner at Small Opening of Cylindrical Valve. Math. Probl. Eng. 2016. [CrossRef]

176. Martinez, J.J.; Deng, Z.D.; Titzler, P.S.; Duncan, J.P.; Lu, J.; Mueller, R.P.; Renholds, J.F. Hydraulic and biological characterization of a large Kaplan turbine. Renew. Energy 2019, 131, 240-249. [CrossRef]

177. Menarin, H.A.; Costa, H.A.; Fredo, G.L.M.; Gosmann, R.P.; Finardi, E.C.; Weiss, L.A. Dynamic Modeling of Kaplan Turbines Including Flow Rate and Efficiency Static Characteristics. IEEE Trans. Power Syst. 2019, 34, 3026-3034. [CrossRef]

178. Turi, F.; Fortes-Patella, R. Numerical methodology to predict and analyze cavitating flows in a Kaplan turbine. In Proceedings of the IOP Conference Series: Earth and Environmental Science; IOP Publishing: Bristol, UK, 2019; Volume 240, p. 22019.

179. Kim, H.-H.; Rakibuzzaman, M.; Kim, K.; Suh, S.-H. Flow and Fast Fourier Transform Analyses for Tip Clearance Effect in an Operating Kaplan Turbine. Energies 2019, 12, 264. [CrossRef]

180. Iovănel, R.G.; Bucur, D.M.; Dunca, G.; Cervantes, M.J. Numerical analysis of a Kaplan turbine model during transient operation. In Proceedings of the IOP Conference Series: Earth and Environmental Science; IOP Publishing: Bristol, UK, 2019; Volume 240, p. 22046.

181. Knapp, R.T.; Daily, J.W. Hammitt. FG Cavitation; McGraw Hill: New York, NY, USA, 1970.

182. Carlton, J.S. Cavitation. In Marine Propellers and Propulsion; Elsevier: Amsterdam, The Netherlands, 2019; pp. 217-260.

183. Lipej, A.; Jošt, D.; Meznar, P.; Djelic, V. Numerical prediction of pressure pulsation amplitude for different operating regimes of Francis turbine draft tubes. Int. J. Fluid Mach. Syst. 2009, 2, 375-382. [CrossRef]

184. Escaler, X.; Egusquiza, E.; Farhat, M.; Avellan, F.; Coussirat, M. Detection of cavitation in hydraulic turbines. Mech. Syst. Signal Process. 2006, 20, 983-1007. [CrossRef]

185. Zhang, H.; Zhang, L. Numerical simulation of cavitating turbulent flow in a high head Francis turbine at part load operation with OpenFOAM. Procedia Eng. 2012, 31, 156-165. [CrossRef]

186. Gohil, P.P.; RP, S. Cavitating Turbulent Flow Study for Low Head Francis Turbine by Transient Analysis. Int. J. Fluid Mach. Syst. 2019, 12, 22-30.

187. Gohil, P.P.; Saini, R.P. Unsteady simulation of cavitating turbulent flow for low head Francis turbine. In Proceedings of the IOP Conference Series: Earth and Environmental Science; IOP Publishing: Bristol, UK, 2019; Volume 240, p. 22007.

188. Tran, C.T.; Long, X.; Ji, B. Vortical structures in the cavitating flow in the Francis-99 draft tube cone under off-design conditions with the new omega vortex identification method. In Proceedings of the Journal of Physics: Conference Series; IOP Publishing: Trondheim, Norway, 2019; Volume 1296, p. 12011. 
189. Yang, J.; Zhou, L.; Wang, Z.; Jiang, X.; Zhou, X.; Ding, J.; Han, W. Numerical investigation of the cavitation dynamic parameter in a Francis turbine draft tube with columnar vortex rope. J. Hydrodyn. 2019, 1-9. [CrossRef]

190. Zhang, Z.; Yu, Z.; Gao, H.; Cheng, N.; Wang, J. Research on the cavitation characteristic improvement of impellers of HL220 turbine. Environ. Earth Sci. 2019, 78, 371. [CrossRef]

191. Zhou, X.; Wu, H.; Shi, C. Numerical and experimental investigation of the effect of baffles on flow instabilities in a Francis turbine draft tube under partial load conditions. Adv. Mech. Eng. 2019, 11, 1687814018824468. [CrossRef]

192. Jia, Y.; Wei, X.; Wang, Q.; Cui, J.; Li, F. Experimental Study of the Effect of Splitter Blades on the Performance Characteristics of Francis Turbines. Energies 2019, 12, 1676. [CrossRef]

193. Nishi, Y.; Kobori, T.; Mori, N.; Inagaki, T.; Kikuchi, N. Study of the internal flow structure of an ultra-small axial flow hydraulic turbine. Renew. Energy 2019, 139, 1000-1011. [CrossRef]

194. Zhou, D.; Gui, J.; Deng, Z.D.; Chen, H.; Yu, Y.; Yu, A.; Yang, C. Development of an ultra-low head siphon hydro turbine using computational fluid dynamics. Energy 2019, 181, 43-50. [CrossRef]

195. Yu, A.; Tang, Q.; Wang, X.; Zhou, D.; Liu, J. Investigation of the Pressure Fluctuation Alleviation in a Hydraulic Turbine by Runner Modification. Water 2019, 11, 1332. [CrossRef]

196. Xu, B.; Jun, H.-B.; Chen, D.; Li, H.; Zhang, J.; Cavalcante Blanco, C.J.; Shen, H. Stability analysis of a hydro-turbine governing system considering inner energy losses. Renew. Energy 2019, 134, 258-266. [CrossRef]

197. Piraisoodi, T.; Maria Siluvairaj, W.I.; Kappuva, M.A.K. Multi-objective robust fuzzy fractional order proportional-integral-derivative controller design for nonlinear hydraulic turbine governing system using evolutionary computation techniques. Expert Syst. 2019, 36, e12366. [CrossRef]

198. Guo, B.; Guo, J. Feedback Linearization and Reaching Law Based Sliding Mode Control Design for Nonlinear Hydraulic Turbine Governing System. Energies 2019, 12, 2273. [CrossRef]

199. Ouadday, R.; Marouene, A.; Morada, G.; Kaabi, A.; Boukhili, R.; Vadean, A. Experimental and numerical investigation on the impact behavior of dual-core composite sandwich panels designed for hydraulic turbine applications. Compos. Struct. 2018, 185, 254-263. [CrossRef]

200. Caishui, H. Three-dimensional Numerical Analysis of Flow Pattern in Pressure Forebay of Hydropower Station. Procedia Eng. 2012, 28, 128-135. [CrossRef]

201. Wei, S.H.; Zhang, L.J. Vibration analysis of hydropower house based on fluid-structure coupling numerical method. Water Sci. Eng. 2010, 3, 75-84.

202. Castelli, F.; Lentini, V.; Trifarò, C.A. 1D seismic analysis of earth dams: the example of the Lentini site. Procedia Eng. 2016, 158, 356-361. [CrossRef]

203. Lian, J.; Wang, H.; Wang, H. Study on Vibration Transmission among Units in Underground Powerhouse of a Hydropower Station. Energies 2018, 11, 3015. [CrossRef]

204. Ma, Z.Y.; Xu, W.; Zhi, B.P. Energy flow transmission analysis on the powerhouse vibration under turbine hydraulic loads. In Proceedings of the IOP Conference Series: Earth and Environmental Science; IOP Publishing: Bristol, UK, 2019; Volume 240, p. 62001.

205. Jing, C.; Yanhui, W.; Yu, G. STRUCTURAL VIBRATION CALCULATION OF UNDERGROUND POWERHOUSE OF LARGE HYDROPOWER STATION AND VIBRATION REDUCTION. Acad. J. Manuf. Eng. 2019, 17.

206. Klun, M.; Zupan, D.; Lopatič, J.; Kryžanowski, A. On the Application of Laser Vibrometry to Perform Structural Health Monitoring in Non-Stationary Conditions of a Hydropower Dam. Sensors 2019, $19,3811$. [CrossRef] [PubMed]

207. Zhou, H.; Xiao, M.; Yang, Y.; Liu, G. Seismic Response Analysis Method for Lining Structure in Underground Cavern of Hydropower Station. KSCE J. Civ. Eng. 2019, 23, 1236-1247. [CrossRef]

208. Wang, X.; Chen, J.; Xiao, M. Seismic damage assessment and mechanism analysis of underground powerhouse of the Yingxiuwan Hydropower Station under the Wenchuan earthquake. Soil Dyn. Earthq. Eng. 2018, 113, 112-123. [CrossRef]

209. Xu, B.; Xia, H. Effect of Damage on Natural Vibration Characteristics of Large Semi-cushion Spiral Case Structure. Arab. J. Sci. Eng. 2019, 44, 4063-4074. [CrossRef]

210. Samii, A.; Lotfi, V. Application of $\mathrm{H}-\mathrm{W}$ boundary condition in dam-reservoir interaction problem. Finite Elem. Anal. Des. 2012, 50, 86-97. [CrossRef] 
211. Watanabe and Kawakami T, H. Characteristics of elementary dynamic behavior for three dimensional seismic response of a fill dam. SOILS Found. 1995, 35, 45-54. [CrossRef]

212. Zhang, R.; Mao, F.; Wu, J.-Z.; Chen, S.-Y.; Wu, Y.-L.; Liu, S.-H. Characteristics and control of the draft-tube flow in part-load Francis turbine. J. Fluids Eng. 2009, 131, 21101. [CrossRef]

213. Xie, J.; Sun, D. Statistics of dam failures in China and analysis on failure causations. Water Resour. Hydropower Eng. 2009, 40, 124-128.

214. Evans, J.E.; Mackey, S.D.; Gottgens, J.F.; Gill, W.M. Lessons from a dam failure. Ohio J. Sci. ohio USA 2000, 100, 121-131.

215. Oboni, F.; Oboni, C.; Oboni, F.; Oboni, C. Examples of Recent Catastrophic Hydro-Dam Accidents. In Tailings Dam Management for the Twenty-First Century; Springer International Publishing: Berlin/Heidelberg, Germany, 2020; ISBN 9783030194475.

216. Oboni, F.; Oboni, C.; Oboni, F.; Oboni, C. Two Recent Catastrophic Tailings Dams Accidents. In Tailings Dam Management for the Twenty-First Century; Springer: Cham, Germany, 2020; pp. 13-22.

217. KC, A.; Lee, Y.H.; Thapa, B. CFD study on prediction of vortex shedding in draft tube of Francis turbine and vortex control techniques. Renew. Energy 2016, 86, 1406-1421. [CrossRef]

218. Liu, X.; Luo, Y.; Karney, B.W.; Wang, W. A selected literature review of efficiency improvements in hydraulic turbines. Renew. Sustain. Energy Rev. 2015, 51, 18-28. [CrossRef]

219. Pan, H.C.; Hong, S.L. Improving the efficiency of a hydro-turbine system by vortex generators. In Proceedings of the Advanced Materials Research; Trans Tech Publications Ltd.: Zürich, Switzerland, 2012; Volume 354, pp. 636-641.

220. Egusquiza, E. Vibration behavior of hydraulic turbines, Application to condition monitoring. In Proceedings of the 2nd IAHR International Meeting of the WG on Cavitation and Dynamic Problems in Hydraulic Machinery and Systems, Timisoara, Romania, 24 October 2007.

221. Li, W.-G.; Zhang, Y.-L. Computational cavitating viscous liquid flows in a pump as turbine and Reynolds number effects. Proc. Inst. Mech. Eng. Part E J. Process Mech. Eng. 2019, 233, 536-550. [CrossRef]

222. Silva, P.A.S.F.; Shinomiya, L.D.; de Oliveira, T.F.; Vaz, J.R.P.; Amarante Mesquita, A.L.; Brasil Junior, A.C.P. Analysis of cavitation for the optimized design of hydrokinetic turbines using BEM. Appl. Energy 2017, 185, 1281-1291. [CrossRef]

223. Girimaji, S.S. Partially-Averaged Navier-Stokes Model for Turbulence: A Reynolds-Averaged Navier-Stokes to Direct Numerical Simulation Bridging Method. J. Appl. Mech. 2006, 73, 413-421. [CrossRef]

224. Lu, T.; Samulyak, R.; Glimm, J. Direct numerical simulation of bubbly flows and application to cavitation mitigation. J. Fluids Eng. 2007, 129, 595-604. [CrossRef]

225. Ji, B.; Luo, X.W.; Arndt, R.E.A.; Peng, X.; Wu, Y. Large eddy simulation and theoretical investigations of the transient cavitating vortical flow structure around a NACA66 hydrofoil. Int. J. Multiph. Flow 2015, 68, 121-134. [CrossRef]

226. Liu, J.; Zhou, Z.; Zhang, X.J. Impacts of sediment load and size on rill detachment under low flow discharges. J. Hydrol. 2019, 570, 719-725. [CrossRef]

227. Kanamura, T.; Ōhashi, K. A structural model for electricity prices with spikes: Measurement of spike risk and optimal policies for hydropower plant operation. Energy Econ. 2007, 29, 1010-1032. [CrossRef]

228. Yucesan, M.; Kahraman, G. Risk evaluation and prevention in hydropower plant operations: A model based on Pythagorean fuzzy AHP. Energy Policy 2019, 126, 343-351. [CrossRef]

229. Pérez-Díaz, J.I.; Chazarra, M.; García-González, J.; Cavazzini, G.; Stoppato, A. Trends and challenges in the operation of pumped-storage hydropower plants. Renew. Sustain. Energy Rev. 2015, 44, 767-784. [CrossRef]

230. Guisández, I.; Pérez-Díaz, J.I.; Wilhelmi, J.R. Assessment of the economic impact of environmental constraints on annual hydropower plant operation. Energy Policy 2013, 61, 1332-1343. [CrossRef]

231. Rocha, M.; da Silva, J.N. A New Method for the Determination of Deformability in Rock Masses; The National Academies of Sciences, Engineering, and Medicine: Washington, DC, USA, 1970.

232. Oberti, G.; Goffi, L.; Rossi, P.P. Study Of Stratified Rock Masses By Means Of Large-Scale Tests With An Hydraulic Pressure Chamber. In Proceedings of the 5th ISRM Congress-International Society for Rock Mechanics and Rock Engineering, Melbourne, Australia, 10-15 April 1983.

233. Zhang, Y.; Su, G.; Liu, B.; Li, T. A novel displacement back analysis method considering the displacement loss for underground rock mass engineering. Tunn. Undergr. Sp. Technol. 2020, 95, 103141. [CrossRef] 
234. Hoek, E.; Diederichs, M.S. Empirical estimation of rock mass modulus. Int. J. Rock Mech. Min. Sci. 2006, 43, 203-215. [CrossRef]

235. Stone, R. Hydropower. The legacy of the Three Gorges Dam. Science 2011, 333, 817. [CrossRef]

236. Zhao, X.; Wu, L.; Qi, Y. The Energy injustice of hydropower: Development, resettlement, and social exclusion at the Hongjiang and Wanmipo hydropower stations in China. Energy Res. Soc. Sci. 2020, 62, 101366. [CrossRef]

237. Orr, S.; Pittock, J.; Chapagain, A.; Dumaresq, D. Dams on the Mekong River: Lost fish protein and the implications for land and water resources. Glob. Environ. Chang. 2012, 22, 925-932. [CrossRef]

238. Chen, A.; Wu, M.; McClain, M.E. Classifying Dams for Environmental Flow Implementation in China. Sustainability 2019, 12, 107. [CrossRef]

239. O'Hanley, J.R.; Pompeu, P.S.; Louzada, M.; Zambaldi, L.P.; Kemp, P.S. Optimizing hydropower dam location and removal in the São Francisco river basin, Brazil to balance hydropower and river biodiversity tradeoffs. Landsc. Urban Plan. 2020, 195, 103725. [CrossRef]

240. Long, P.D.; Dung, N.T. Geotechnics for Sustainable Infrastructure Development; Springer Nature: Berlin/Heidelberg, Germany, 2019; Volume 62, ISBN 9811521840.

241. Allawi, M.F.; Jaafar, O.; Mohamad Hamzah, F.; Abdullah, S.M.S.; El-shafie, A. Review on applications of artificial intelligence methods for dam and reservoir-hydro-environment models. Environ. Sci. Pollut. Res. 2018, 25, 13446-13469. [CrossRef]

242. Leitner, P.; Hauer, C.; Graf, W. Habitat use and tolerance levels of macroinvertebrates concerning hydraulic stress in hydropeaking rivers-A case study at the Ziller River in Austria. Sci. Total Environ. 2017, 575, 112-118. [CrossRef] [PubMed]

243. Carvalho, L.; Mackay, E.B.; Cardoso, A.C.; Baattrup-Pedersen, A.; Birk, S.; Blackstock, K.L.; Borics, G.; Borja, A.; Feld, C.K.; Ferreira, M.T.; et al. Protecting and restoring Europe's waters: An analysis of the future development needs of the Water Framework Directive. Sci. Total Environ. 2019, 658, 1228-1238. [CrossRef] [PubMed]

244. Huđek, H.; Žganec, K.; Pusch, M.T. A review of hydropower dams in Southeast Europe-distribution, trends and availability of monitoring data using the example of a multinational Danube catchment subarea. Renew. Sustain. Energy Rev. 2020, 117, 109434. [CrossRef] 